\title{
LUT
}

University

\section{Scenarios for sustainable energy in Scotland}

Child Michael, llonen Roope, Vavilov Mihail, Kolehmainen Mikko, Breyer Christian

This is a Final draft version of a publication

published by John Wiley \& Sons

in Wind Energy

DOI: $10.1002 /$ we.2314

Copyright of the original publication: (c) 2019 John Wiley \& Sons, Ltd.

Please cite the publication as follows:

Child M, llonen R, Vavilov M, Kolehmainen M, Breyer C. Scenarios for sustainable energy in Scotland. Wind Energy. 2019;1-19. https://doi.org/10.1002/we.2314

This is a parallel published version of an original publication.

This version can differ from the original published article. 


\title{
Scenarios for sustainable energy in Scotland
}

\author{
Michael Child D | Roope Ilonen I Mihail Vavilov | Mikko Kolehmainen I Christian Breyer
}

Lappeenranta University of Technology, Skinnarilantie 34, 53850 Lappeenranta, Finland

Correspondence

Michael Child, Lappeenranta University of Technology, Skinnarilantie 34, 53850

Lappeenranta, Finland.

Email: Michael.Child@lut.fi

\begin{abstract}
High shares of renewable energy, particularly wind power, were modelled in several future scenarios for the Scottish energy system. In the first part of this work, it was determined that Scotland could produce the equivalent baseload power for supply to England at a lower overall cost ( $99 € / \mathrm{MWh}$ ) than the proposed subsidized price (112 $€ / M W h)$ to be paid for electricity generated from the proposed Hinkley Point $C$ nuclear power plant. This cost includes all extra generation capacity and transmission lines. In the second part of this work, it was determined that a $100 \%$ renewable energy system could be achieved at an annualized cost of $10.7 \mathrm{~b} € / \mathrm{a}$, approximately $8 \%$ less than the $11.7 \mathrm{~b} € /$ a expected for an energy system composed of $75 \%$ renewable energy. In the $100 \%$ renewable energy system, cost savings are achieved through effective energy storage, sector integration, and flexible generation from dispatchable renewable energy resources, such as hydropower $\left(1.7 \mathrm{GW}_{\mathrm{e}}\right)$, bioenergy, and synthetic fuels. Complementary resources to $23.4 \mathrm{GW}_{\mathrm{e}}$ of wind power also included solar photovoltaics $\left(10.1 \mathrm{GW}_{\mathrm{e}}\right)$, tidal power $\left(1.5 \mathrm{GW}_{\mathrm{e}}\right)$, and wave power $\left(0.3 \mathrm{GW}_{\mathrm{e}}\right)$. It was also determined that carbon capture and utilization would be a preferable strategy to carbon capture and storage for Scotland. Complete defossilization of the Scottish energy system appears feasible by 2050 , given the assumptions used in this study.
\end{abstract}

\section{KEYWORDS}

$100 \%$ renewable energy, EnergyPLAN, energy system modelling, flexible generation, Scotland, wind energy

\section{1 | INTRODUCTION}

The landmark Paris Agreement acknowledged that climate change is an urgent and common concern of humankind, and emphasized the urgent need to limit increases in global average temperature through accelerating reductions in global greenhouse gas (GHG) emissions. ${ }^{1}$ As modern energy systems represent approximately three-quarters of these emissions, ${ }^{2}$ there is an equally urgent need to initiate change in the way energy is both produced and consumed on a global level. At the same time, the impacts of energy systems go beyond those related to climate change, ${ }^{3}$ and so there is an opportunity to implement a comprehensive transition towards more resilient and sustainable energy systems that fully respect known planetary boundaries ${ }^{4,5}$ and criteria for sustainability. Fully renewable energy system scenarios are argued to fulfil the most comprehensive set of sustainability criteria for the future. ${ }^{6}$

Abbreviations: b, billion; BEV, battery electric vehicle; CCS, carbon capture and storage; CCU, carbon capture and utilization; CCUS, carbon capture utilization and storage; FTE, full-time equivalent; GDP, gross domestic product; GHG, greenhouse gas; Gl, government intervention; GW/GWh, gigawatt/gigawatt hour; kg, kilogram; km, kilometer; LNG, liquified natural gas; m, million; MCl, manufacturing, construction, and installation; MJ, megajoule; MW/MWh, megawatt/megawatt hour; O\&M, operations and maintenance; odt, oven dry ton; pkm, passenger kilometer; PtG, power-to-gas; PtL, power-to-liquids; PV, photovoltaics; RE, renewable energy; SNG, synthetic natural gas; TWh, Terawatt hour; UK, United Kingdom; UT, utilization; V2G, vehicle-to-grid; VRE, variable renewable energy; WACC, weighted average cost of capital

Subscripts: e, electric units; th, thermal units; p, nominal or peak capacity 
Scotland has amongst the most ambitious climate change legislation in the world, targeting $42 \%$ GHG emissions reductions by 2020 and $80 \%$ by $2050 .^{7}$ Most recently, a draft climate change bill was introduced that may set a target of $90 \%$ reduction by 2050 with the ultimate aim of achieving net zero emissions. ${ }^{8}$ To achieve these goals, and to ensure future sustainability, Scotland's priority is "to support energy efficiency, develop Scotland's huge renewable resource and to promote storage and flexibility." Notably, the Government of Scotland has clearly stated that criticism of the development of nuclear power in the United Kingdom (UK), particularly the proposed station at Hinkley, is wholly justified, "on the grounds that it is risky, expensive, and a bad outcome for UK consumers." ${ }^{\prime 9}$ Furthermore, Scotland's current fleet of nuclear power plants are nearing their end of life, with the Hunterston B and Torness plants expected to operate no later than 2030. At the same time, recent questions over the safety and reliability of the Hunterston B and other Advanced Gas-Cooling Reactors (including Torness) may trigger further discussion on lifetime extensions. ${ }^{10}$

Other official plans to achieve decarbonization involve Carbon Capture Utilization and Storage (CCUS), especially in relation to carbon intensive industrial processes, such as aluminium, steel, ammonia and cement production. ${ }^{9}$ However, despite the fact that the Scottish Government has strongly advocated Carbon Capture and Storage (CCS) development, there are several criticisms on the economic and technical viability of such projects. ${ }^{6,11}$ Until serious issues related to economic, social, and environmental risks are effectively dealt with, CCS will remain too risky for investors. ${ }^{12}$ In addition, UK Ministers removed $1 \mathrm{~b} £$ in funding of CCS projects in 2015, further reducing the probability of CCS development in the near future. At the same time, Carbon Capture and Utilization (CCU) offers several benefits and opportunities that appear to match Scottish targets, such as achieving climate change objectives, establishing a circular economy, enhancing energy security, and promoting deployment of renewable energy. ${ }^{13}$

For these reasons, the prospect of a 100\% renewable energy system for Scotland appears more realistic. Moreover, the Scottish Government already has a target of $100 \%$ power supply by $2020 .^{7}$ Studies featuring energy systems based on $100 \%$ renewable energy (RE) have been proposed for several regions of the world, and globally. ${ }^{14-18}$ This increasing body of literature shows that $100 \%$ RE energy systems are neither infeasible nor prohibitively expensive. Rather, several of these studies show that $100 \%$ RE energy systems could be least cost solutions by 2050 and beyond. In addition, recent reports claim that significant RE-based employment can be created both internationally and domestically, and that the economics of renewable energy production are superior to low carbon alternatives. ${ }^{11,19}$ It is expected that the renewables and low carbon industry already employs approximately 21000 people in Scotland, and the many billions of Scottish pounds in future investments will result in many thousands of more jobs. ${ }^{20}$

Wind energy resources in the northern UK, particularly Scotland, are amongst the best in the world. However, despite this vast potential on technical and economic bases, wind energy is a controversial topic within the UK. ${ }^{21}$ On the surface, it appears that wind energy enjoys greater social and political acceptance in Scotland than in the UK as a whole, which introduces a second major divergence in energy policy between Scotland and the UK. As renewable energy resources in Scotland are so abundant, ${ }^{7,20}$ it seems reasonable to question whether such resources could be sufficient to provide power to other parts of the UK, thereby creating less need for controversial nuclear power. Considering the variable nature of wind energy, this poses problems if the intention is to have it substitute baseload power provision. The role of storage technologies and flexibility measures to support high shares of variable renewable energy (VRE) appears obvious, but the roles of each have yet to be fully described.

The transport and industrial sectors may be among the most difficult to achieve full defossilization. While scenarios developed for the future of energy in Scotland describe how passenger and light-duty vehicles can be either electrified or fuelled by hydrogen, ${ }^{9}$ there has been no reporting of how heavy-duty trucking, shipping, or aviation could achieve emission reductions. Likewise, development of CCS appears to be linked to mitigating industrial emissions associated with industry, particularly those from ammonia, aluminium, steel, and cement production. However, most of these important industrial activities could be defosillized without the need for CCS. Ammonia can be produced from a combination of renewable hydrogen and nitrogen from air. ${ }^{22}$ Hydrogen reduction can result in defossilization in the metals industry. ${ }^{23,24}$ And while some of the $\mathrm{CO}_{2}$ emissions associated with calcination in the cement industry may be unavoidable, energetic needs (power, heat) during cement making can be provided by renewable-based sources. ${ }^{25}$ Any unavoidable emissions from these or other industrial activities could be candidates for potential carbon capture and utilization (CCU) schemes. ${ }^{13}$

Given these observations, this research seeks to investigate whether a $100 \%$ renewable energy system could be technologically feasible and economically competitive for Scotland by 2050. In addition, this work will investigate whether Scotland could feasibly provide sufficient levels of baseload power to the rest of the UK by 2030 that would compensate for the equivalent power delivered by the controversial, proposed Hinkley Point $\mathrm{C}$ nuclear power plant. In both cases, the roles of various RE and storage technologies will be examined in addition to energy efficiency and flexibility measures.

\section{2 | METHODOLOGY}

\section{1 | The EnergyPLAN simulation tool}

The EnergyPLAN simulation tool was developed at Aalborg University in Denmark as a tool to simulate future energy system scenarios. ${ }^{26}$ Since its development in 1999, it has undergone constant improvement, and it has been used to simulate the energy systems of multinational ${ }^{27}$ and

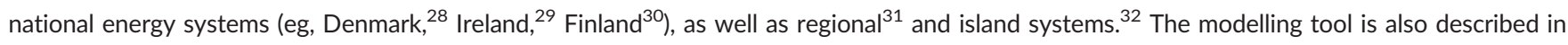
detail in relation to other available modelling tools ${ }^{33}$ and has also been classified as a simulation tool as opposed to an optimization tool. ${ }^{34}$ At 
the same time, EnergyPLAN simulations generally take no more than seconds to perform, which allows the modeller to quickly see how changing input parameters affects the result. In this manner, the modeller can become an agent of optimization to some extent.

The EnergyPLAN tool balances the energy system for every hour of the year, and needs detailed deterministic inputs of various parameters of energy supply and demand. Hourly profiles of energy demands and resource availabilities are among the main inputs to EnergyPLAN. In addition, users input power plant and storage capacities, efficiencies, costs, and regulation strategies that are appropriate for the scenario being simulated. Outputs from the tool are energy balances, annual production figures, fuel consumption, carbon emissions, imports and exports, and total costs. Version 12.3 of EnergyPLAN was used in this research. Figure 1 depicts the main inputs and outputs of EnergyPLAN.

A first scenario for Scotland was devised using the EnergyPLAN tool for 2015. Upon validation that the tool was suitable to represent the Scottish energy system, two further scenarios were developed for 2030, and two for 2050. Numerical results from EnergyPLAN were collected, tabulated, and visualized for all scenarios. A comprehensive set of tables and figures are presented in the sections that follow; however, more comprehensive information is also found in the Supporting Information.

\subsection{Description of the Scottish energy system}

The country of Scotland is located in the northern third of Great Britain and is a member of the United Kingdom. Scotland has grown in population by $5 \%$ in the last decade to reach 5.4 million inhabitants. In addition, it has a gross domestic product (GDP) of approximately 150 bf, or about $32000 €$ per capita. Land area is approximately $77980 \mathrm{~km}^{2}$, and the country is bordered by England in the south, as well as the North Sea in the north and east, and the Irish Sea in the west. The terrain of Scotland is mostly mountainous but also includes highly populated lowland areas, including the cities of Glasgow and Edinburgh (Figure 2). Due to its topography and location, Scotland has amongst the best onshore and offshore F2 wind resources in the world. ${ }^{20}$ It also has good solar radiation with a high level of seasonality ${ }^{35,36}$ (Figure 3). The main installed capacities (> 20 F3 $\mathrm{MW}_{\mathrm{e}}$ ) currently found in the Scottish energy system are shown in Figure $4 .{ }^{37}$

Other renewable energy resources available in Scotland include hydropower, bioenergy, wave energy, and tidal energy. For the former, hydropower has represented approximately $10 \%$ of Scottish electricity consumption in recent years. ${ }^{9}$ Current installed capacity is currently around $1500 \mathrm{MW}$, and a further 400 to $500 \mathrm{MW}$ of small to medium size run-of-river development appears economically viable. ${ }^{38}$ While the potential of new hydropower development appears low compared to other renewables, the high capacity factors of Scottish hydropower and flexibility of pumped hydro storage will result in its continued importance to the future of energy in Scotland.

Scotland also has vast potential for bioenergy. Andersen et al ${ }^{39}$ outline how biomass energy could make a notable contribution to Scotland's renewable energy needs. However, much of this contribution was assumed to come from short rotation coppice (SRC) energy crops, such as willow. While SRC energy crops may aid in meeting short-term needs over the transition towards sustainability, it is questionable whether such use of land is appropriate given that the same land may be used for other purposes, such as agriculture. In cases where the land cannot be used for agriculture, it may also represent greater efficiency to dedicate the land to solar PV. For this reason, only the potential energy from forestry residues are considered in this study. This potential is estimated to be 3 to $4 \mathrm{M} \mathrm{odt.}{ }^{39}$ Using a conservative heating value for wood fuels of

Inputs

Annual demands:

- Electricity

- District heating

- Individual heating

- Fuels for industry

- Fuels for transport

Capacities and efficiencies:

- Thermal power plants

- Hydropower

- RE technologies

- Storage technologies

- Electric, Thermal, Gas, Liquid fuels

Cost data:

- Fuel costs

- GHG emission factors and costs

- Interest rate

- Capital expenditures

- Operational expenditures

Hourly distributions:

- Electricity and heating demands

- Variable energy resource supply

- Transportation demand

- Fixed import or export
EnergyPLAN

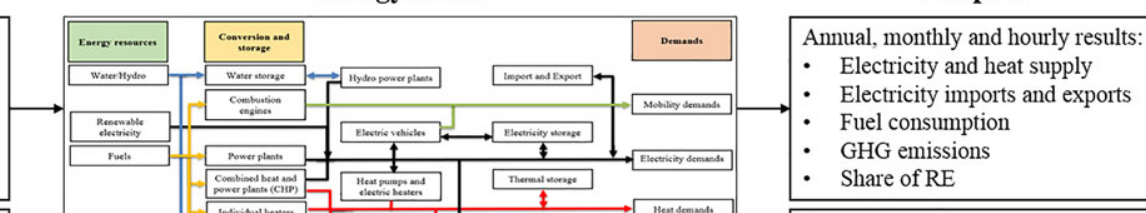

Annualised energy system costs:

- Capital expenditures

- Operations and maintenance

- Fixed

- Variable

- Import and export

- GHG emissions
Regulation:

- Technical limitations

- Balancing demands

- External electricity market parameters

- Transmission capacity

- Excess electricity management 


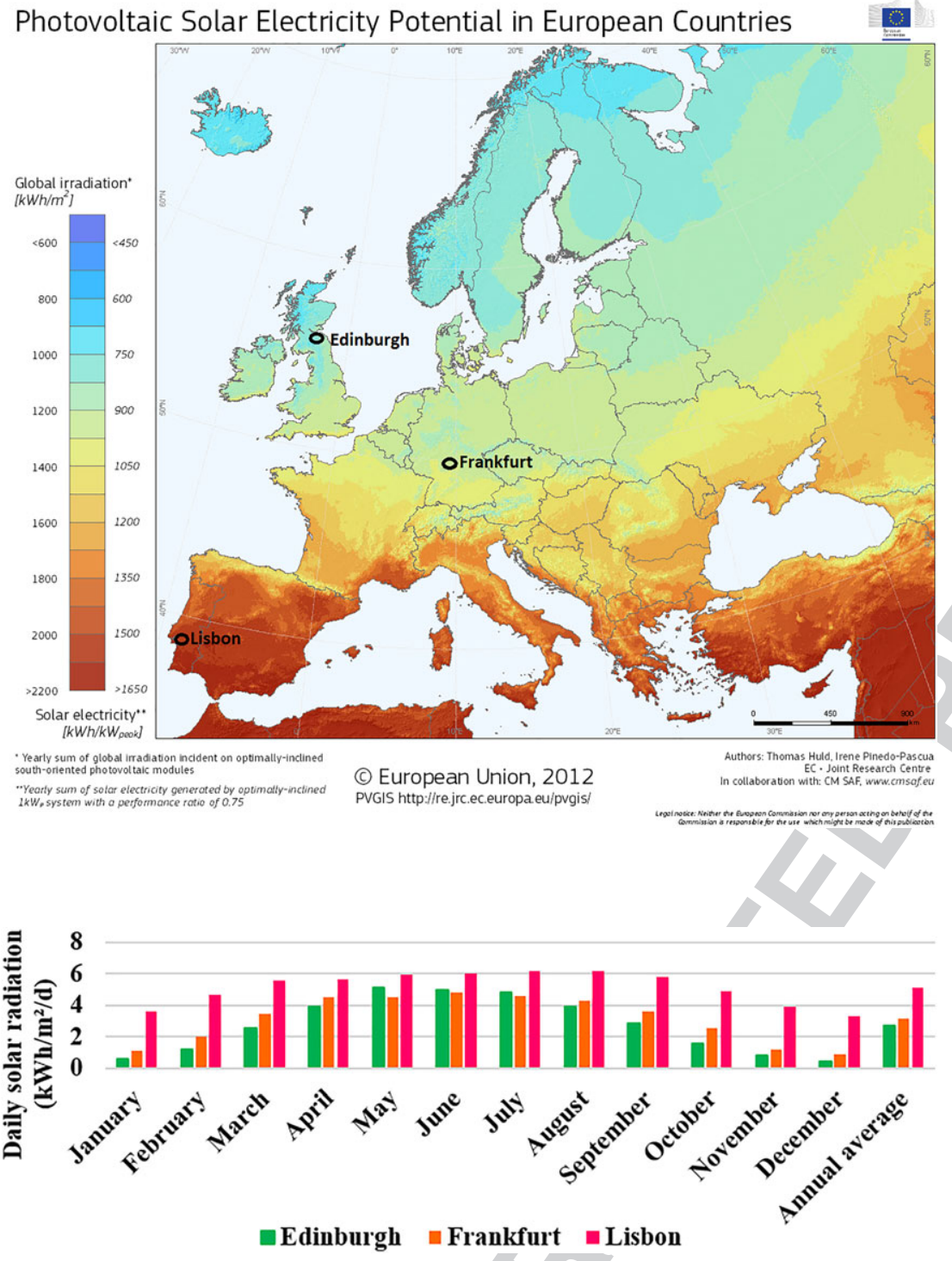

FIGURE 2 Solar electricity potential in Europe including Edinburgh, Scotland. Source: [35, 36]. Copyright European Union, 19952018 [Colour figure can be viewed at wileyonlinelibrary.com]
FIGURE 3 Daily solar radiation on a horizontal surface for three cities in Europe by month and annual average. Data source: [35, 36] [Colour figure can be viewed at wileyonlinelibrary.com]

$18 \mathrm{MJ} / \mathrm{kg}$, this amount of bioenergy represents 15 to 20 TWh of fuel. In this work, a value of 15 TWh of biomass fuel was used as an upper limit of the potential although it must be acknowledged that the potential could be significantly higher.

Scotland has been at the forefront of wave and tidal power development, and enjoys abundant natural marine resources. ${ }^{40}$ However, the exploitation of these resources is somewhat constrained by the absence of electricity grid infrastructure in the most promising resource areas, the harshness of the marine environment, the distance of the resource to population centres, and the high current cost of wave and tidal energy in comparison to wind and solar PV. Despite the abundance of marine resources, it is unlikely that the exploitable capacities of $14 \mathrm{GW}$ of wave power and $7.5 \mathrm{GW}$ of tidal power ${ }^{38}$ will ever be developed, and Scottish Government targets are modest by comparison. At the same time, marine energy development remains a key area of innovation for Scottish industry and is actively being supported. ${ }^{9}$

Scotland currently has four nuclear reactors in operation: two 500-MW reactors at the Hunterston B Power Station that could operate until around 2023, and two 682-MW reactors at the Torness Nuclear Power Station that could operate until 2030, depending on lifetime extensions. However, recent Scottish governments have opposed the construction of new nuclear power plants given the prohibitive economics of current technologies in comparison to the lower costs of renewable energy and storage technologies ${ }^{9}$ which is confirmed by independent analyses. ${ }^{11,41}$ For these reasons, nuclear power generation in Scotland is only considered for the 2015 scenario.

In 2015, total final energy consumption in Scotland was 152.3 TWh, including 36.6 TWh of electricity (from total generation of 50.0 TWh), 78.0 TWh of heat (excluding electrical), and 37.8 TWh of transport fuels (excluding electrical). Renewables represented $27.2 \mathrm{TWh}$ of this total, or $17.8 \%{ }^{42}$ This places Scotland very close to its 2020 target of at least $20 \%$. In addition, Scotland is ahead of both the UK as a whole (8.2\%) and the European Union (16.7\%). A breakdown of transport and heat sector consumption and electricity generation is seen in Figure 5.

The Scottish Government published an energy strategy document in 2017, which clearly outlines targets and aims for the future. ${ }^{9}$ For 2030 , key elements of the strategy include achieving the equivalent of $50 \%$ of consumption in all energy sectors from renewable sources, and a productivity of energy use increase by $30 \%$ across the entire Scottish economy. For 2050, two guiding scenarios have been created: An Electric Future 

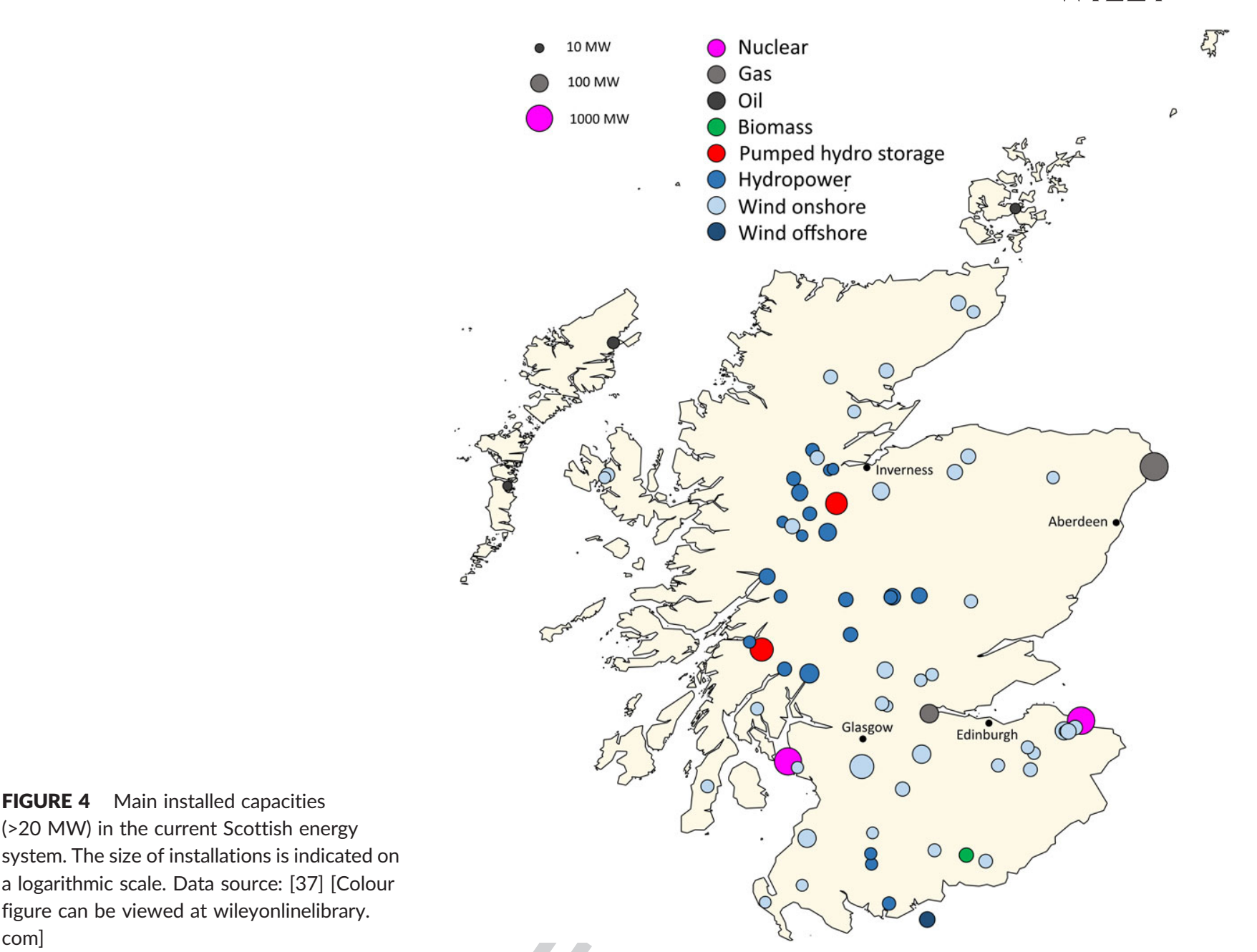

FIGURE 4 Main installed capacities (>20 MW) in the current Scottish energy system. The size of installations is indicated on a logarithmic scale. Data source: [37] [Colour figure can be viewed at wileyonlinelibrary. com]

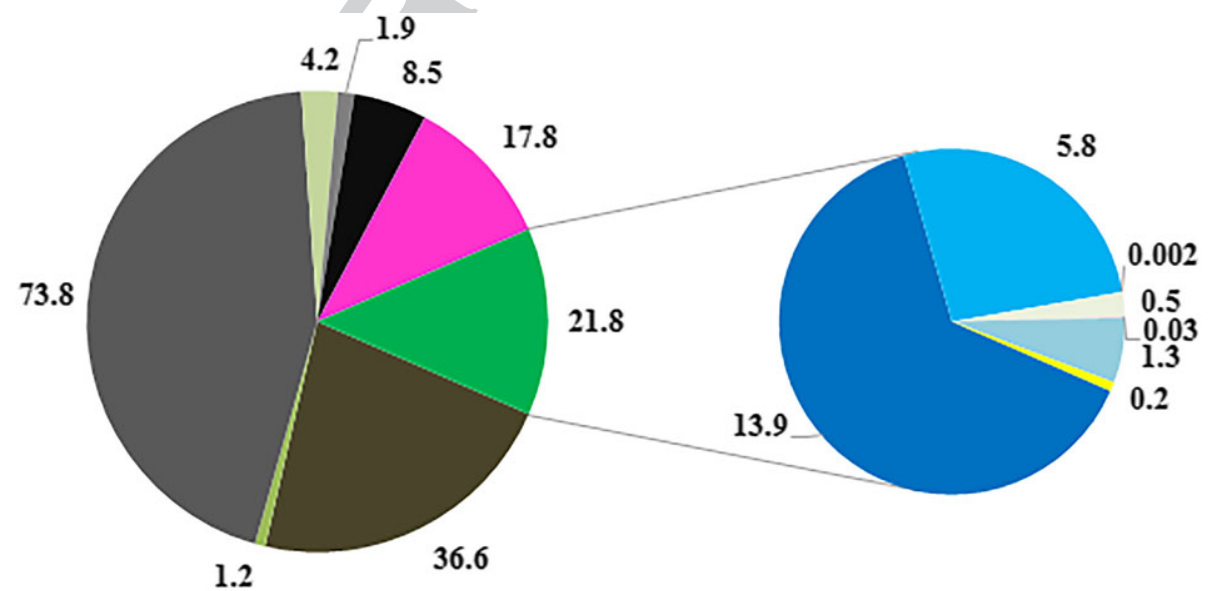

1.2

$\square$ Fossil transport fuels

F ossil heat fuels

$\because \mathrm{Gas}$

Nuclear

a Wind

a Wave / tidal

- Sewage gas

Solar PV
- Renerable transport biofuels

Renerrable heat fuels

- Coal

- Renewable electricity

n Hydro

Landfill gas

- Other biofuels

FIGURE 5 Final consumption in the heat and transport sectors, and electricity generation in Scotland in $201 . m$ breakdown of renewable electricity generation appears on the right. Data source: [41] [Colour figure can be viewed at wileyonlinelibrary.cc 
and A Hydrogen Future. It is stated that the future will most likely see a mixture of both scenarios in reality. The main highlights of An Electric Future include electricity meeting $80 \%$ of residential energy demand by electricity, all cars and light goods vehicles being powered by electricity, $70 \%$ electrification of the service sector, and $30 \%$ reduction of final energy consumption compared to 2015 . A Hydrogen Future features $60 \%$ of residential energy demand being met by hydrogen, all cars and light goods vehicles being powered by hydrogen, 10 million tonnes of GHGs being captured and stored across industry, and a 60\% increase in gas demand (including natural gas, LNG, biogas, biomethane, SNG, and hydrogen).

\section{3 | Description of scenarios}

In total, five scenarios were developed for the Scottish energy system: one for 2015, two for 2030, and two for 2050 . Each of the scenarios is described below. Main inputs for each scenario are summarized in Tables 1 and 2. Further details can be found in the Supporting Information.

\subsection{1 | Scenario 2015}

The 2015 scenario represents a reference scenario that is based on known data about the Scottish energy system. This scenario serves two main purposes. First, results of the analysis can be used to calibrate the EnergyPLAN tool and confirm whether it can adequately reflect the Scottish energy system. This is achieved in a similar manner to other studies ${ }^{30,43,44}$ which compared some key outputs of the EnergyPLAN simulation to actual energy statistics from a reference year. Table 3 shows that EnergyPLAN is reasonably accurate in representing the Scottish energy T3 system. At the same time, it should be kept in mind that EnergyPLAN was not designed to simulate existing energy systems. EnergyPLAN optimizes the use of energy system assets in a very different manner than what occurs in real life. It also assumes full availability of assets throughout the year, which is rarely the case in reality. For these reasons, fuel use in condensing power plants, CHP plants, and import/export values can differ, as seen in Table 3. In addition, the hourly scheduling of assets could differ significantly even though annual values may appear quite similar. Second, future scenarios can be compared to this reference scenario on technological and economic grounds.

TABLE 1 Final energy consumption (TWh) for each scenario

\begin{tabular}{|c|c|c|c|c|c|}
\hline & \multicolumn{5}{|c|}{ Final Energy (TWh) } \\
\hline & 2015 & 2030 Basic & 2030 Hinkley & $205075 \%$ RE & $2050100 \%$ RE \\
\hline Electricity $^{a}$ & 32.32 & 37.13 & 37.13 & 44.77 & 42.84 \\
\hline Transport & 49.49 & 45.05 & 45.05 & 32.70 & 32.70 \\
\hline Industry ${ }^{b}$ & 36.39 & 34.21 & 34.21 & 26.00 & 24.50 \\
\hline
\end{tabular}

${ }^{a}$ Excludes export, electricity for heat, and electricity for transport.

${ }^{b}$ Excludes electricity.

TABLE 2 Installed capacities for main production and storage technologies for each scenario. All values are expressed in electrical units with the exception of PtG- $\mathrm{CH}_{4}$, which is expressed as units of gas production

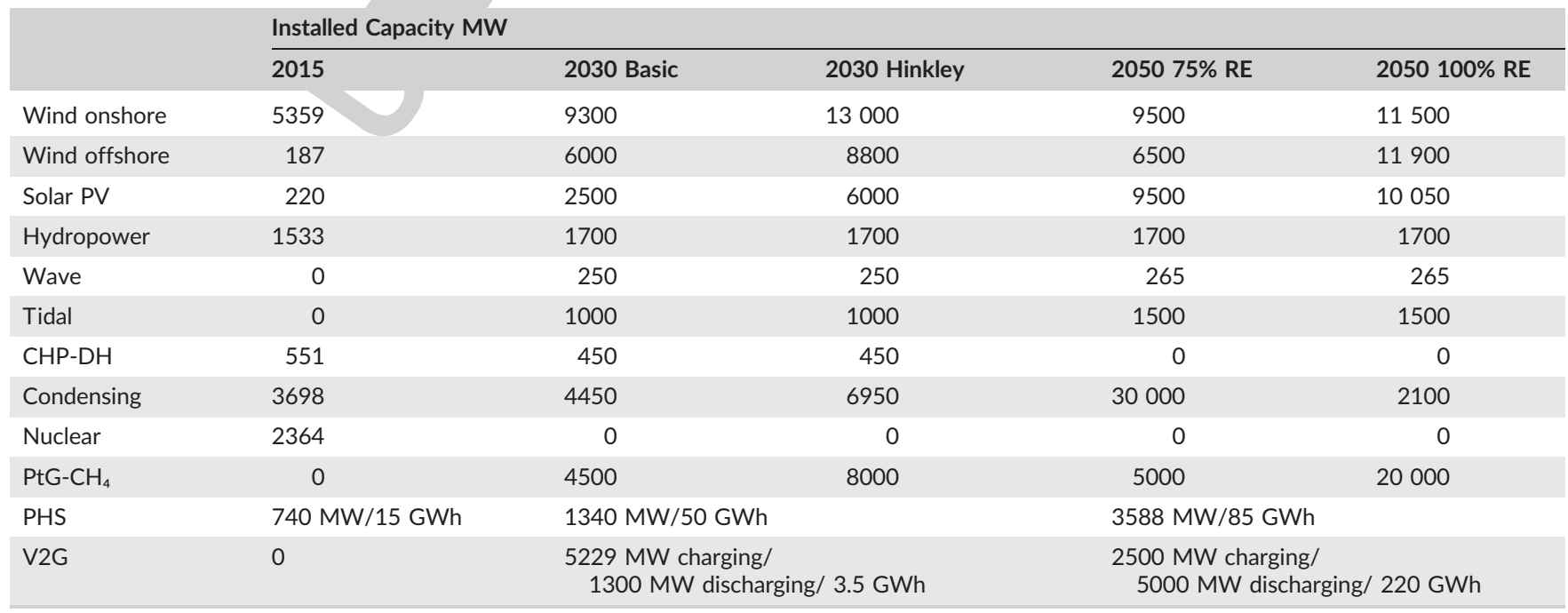


TABLE 3 Comparison of EnergyPLAN results with actual data for Scotland

\begin{tabular}{|c|c|c|c|}
\hline Parameter & EnergyPLAN Fuel Results (TWh) & Actual Annual Results (TWh) & Difference \\
\hline Condensing power plant electricity & 8.89 & 10.38 & 1.49 \\
\hline CHP electricity & 4.55 & 2.30 & 2.25 \\
\hline CHP heat & 5.50 & 6.10 & 0.6 \\
\hline Nuclear & 17.76 & 17.76 & 0 \\
\hline Wind & 13.86 & 13.91 & 0.05 \\
\hline Solar & 0.17 & 0.18 & 0.01 \\
\hline Hydropower & 5.82 & 5.82 & 0 \\
\hline Export & 14.63 & 14.79 & 0.04 \\
\hline $\mathrm{CO}_{2}$ emissions & 42.13 & 43.30 & 1.17 \\
\hline
\end{tabular}

\subsection{2 | Scenario 2030 basic}

This scenario was designed to represent achievement of the 2030 targets described online. ${ }^{9}$ The inputs made to EnergyPLAN related to the elements of this scenario were meant to represent, as closely as possible, a generation scenario already developed for the Scottish power system. ${ }^{45}$ The main aim of this scenario is to develop a progressive mix of renewable and thermal generation up to 2030 that covers up to double the electricity requirements of Scotland in 2020. It was also assumed that the nuclear power plants currently in operation would no longer be active and that new nuclear power plants would not be constructed. As the above scenario contained assumptions only about the power sector, another report was used as the basis for assumptions made for the heat and transport sectors. ${ }^{46}$ It was therefore assumed that $11 \%$ of heat demand (non-electric) would come from renewables, $20 \%$ of transport fuels would be renewable, and that renewables would make up $30 \%$ of all final energy consumed. Further information about the heating sector was compiled from a scenario for 2030 developed for the Scottish heating sector. $^{47}$ The scenario selected was one that showed high levels of Government intervention and uptake of renewables (Scenario 4: High GI, High UT). In the end, it must be acknowledged that although the 2030 Basic scenario is an amalgam of several other, it was deemed by the authors to be a reasonable representation of the main goals of each.

\subsection{3 | Scenario 2030 Hinkley}

This scenario is identical in nature to the 2030 Basic scenario except that an additional baseload electricity demand of 24.3 TWh is satisfied. This amount of electricity represents the expected annual electricity production of the Hinkley Point $\mathrm{C}$ nuclear power plant. It is likewise assumed that a new interconnection of $3200 \mathrm{MW}$ would be built to distribute this energy to northern England. This choice was made to simulate the proposed 3200-MW Hinkley C station running at $90 \%$ capacity for each hour of the year. The cost of this interconnection follows assumptions from Connolly. ${ }^{48}$ Accordingly, capital expenditures (capex) are assumed to be $1.2 \mathrm{M} € / \mathrm{MW}$, operations and maintenance costs are assumed to be $1 \%$ of capex/a, and the lifetime is set at 40 years. The purpose of this scenario is to determine the economic feasibility of providing extra renewable baseload electricity from Scotland in place of the Hinkley Point $\mathrm{C}$ nuclear power plant.

\subsection{4 | Scenario $205075 \%$ RE}

This scenario was designed to represent achievement of the 2050 targets described online ${ }^{9}$ (An Electric Future). In addition, the creation of this scenario was influenced by the High GI, High UT scenario mentioned above concerning the future of the heating sector to $2050 .{ }^{47}$ District heating demand of 5 TWh is provided by large, ground source compression heat pumps with coefficient of performance of 4.6 , and seasonal thermal storage of $6 \mathrm{GWh}$. This scenario is one that allows Scotland to achieve the minimum goals of the Paris Agreement through the reduction of GHGs by $80 \%$ from baseline levels in 1990 . A key feature of this scenario is an assumed high penetration of electrified transport. In total, 8.2 TWh of electricity is used to satisfy driving demands of electric vehicles. The majority of this electrified transport (6.6 TWh) would represent flexible charging, with the remainder classified as dump charging that would occur in the evening/night hours (see Figure 7). Flexibly charged vehicles also F7 participate in vehicle-to-grid services, whereby they could provide electricity back to the grid when necessary. It was assumed that approximately 2.5 million vehicles would participate in V2G services and that each had a 90-kWh battery on average. This totalled $220 \mathrm{GWh}$ of storage with maximum charging power of $25 \mathrm{GW}$ and maximum discharging power of $5 \mathrm{GW}$. The assumption was that while all V2G vehicles would participate in smart charging, only about $20 \%$ would opt to give electricity back to the grid. However, discharging power is limited further by EnergyPLAN to be no more than the total capacity of thermal power plants (see Table 2) and would not exceed $3 \mathrm{GW}$ in this scenario. No other restriction to V2G services are assumed. 


\subsection{5 | Scenario 2050 100\%RE}

This scenario is identical in nature to the $205075 \%$ RE scenario with the exception that the target was a completely defossilized energy system based on $100 \%$ renewable energy. A key feature of this scenario is the complete defossilization of the transport sector. In addition to the V2G services described in the $205075 \%$ RE scenario, synthetic fuels are created from the Power-to-Liquids process. This involves hydrogen from electrolysis and $\mathrm{CO}_{2}$ from direct air capture (DAC) being combined with heat and electricity to create a syngas that can be transformed to liquid fuels via the Fischer-Tropsch process. Fuels are created in the ratio of 1:1:2 for petrol, diesel, and kerosene (jet fuel), respectively. Another key feature was the defossilization of the industrial sector, with much broader use of the power-to-gas function to create synthetic natural gas. Fuel use in the industry and transport sectors are shown in the Supporting Information (Figures A2 and A3). In this scenario, seasonal thermal storage is increased to $10 \mathrm{GWh}$.

\subsection{Data and assumptions}

The following section describes the background data gathered for the Scottish energy system. This includes weather data, load data, and assumptions regarding costs. Further information can be found in the Supporting Information.

\subsection{1 | Weather data}

In a manner described in Bogdanov and Breyer, ${ }^{49}$ real weather data was collected for a complete calendar year from NASA SSE and reprocessed by the German Aerospace Center. ${ }^{50,51}$ Capacity factors for wind and solar energy production are found in Figure 6 below. Wind power production was F6 based on the power curve of an Enercon E-101 wind turbine (3.5 MW), and solar power production was based on optimally tilted, fixed solar PV systems. While EnergyPLAN does not specifically account for the spatial variation of generation technologies, the hourly generation distributions developed for these technologies follow the 30-30-20-10-10 rule defined in Connolly, ${ }^{48}$ whereby $30 \%$ of the installed capacities are found in the $10 \%$ best sites, a further $30 \%$ are found in the next $10 \%$ best sites, $20 \%$ are found in the next $10 \%$ best sites, and so on. This ensures a broader distribution of capacities throughout the $50 \%$ best sites instead of assuming all the capacities are found in sites with the highest capacity factors. This also introduces a possible smoothing effect in the generation profiles that will be similar to what would be witnessed in reality over large distances. Lastly, this may also account for the fact that locations with high capacity factors may also be excluded due to land use restrictions. Assumed full load hours for wind and solar-based generation technologies in $0.45^{\circ} \times 0.45^{\circ}$ resolution are found in the Supporting Information (Figure A1). Land use for onshore wind and solar PV can be estimated based on the installed capacities listed in Table 2. Assuming land use of $8.4 \mathrm{MW} / \mathrm{km}^{2}$ for onshore wind and
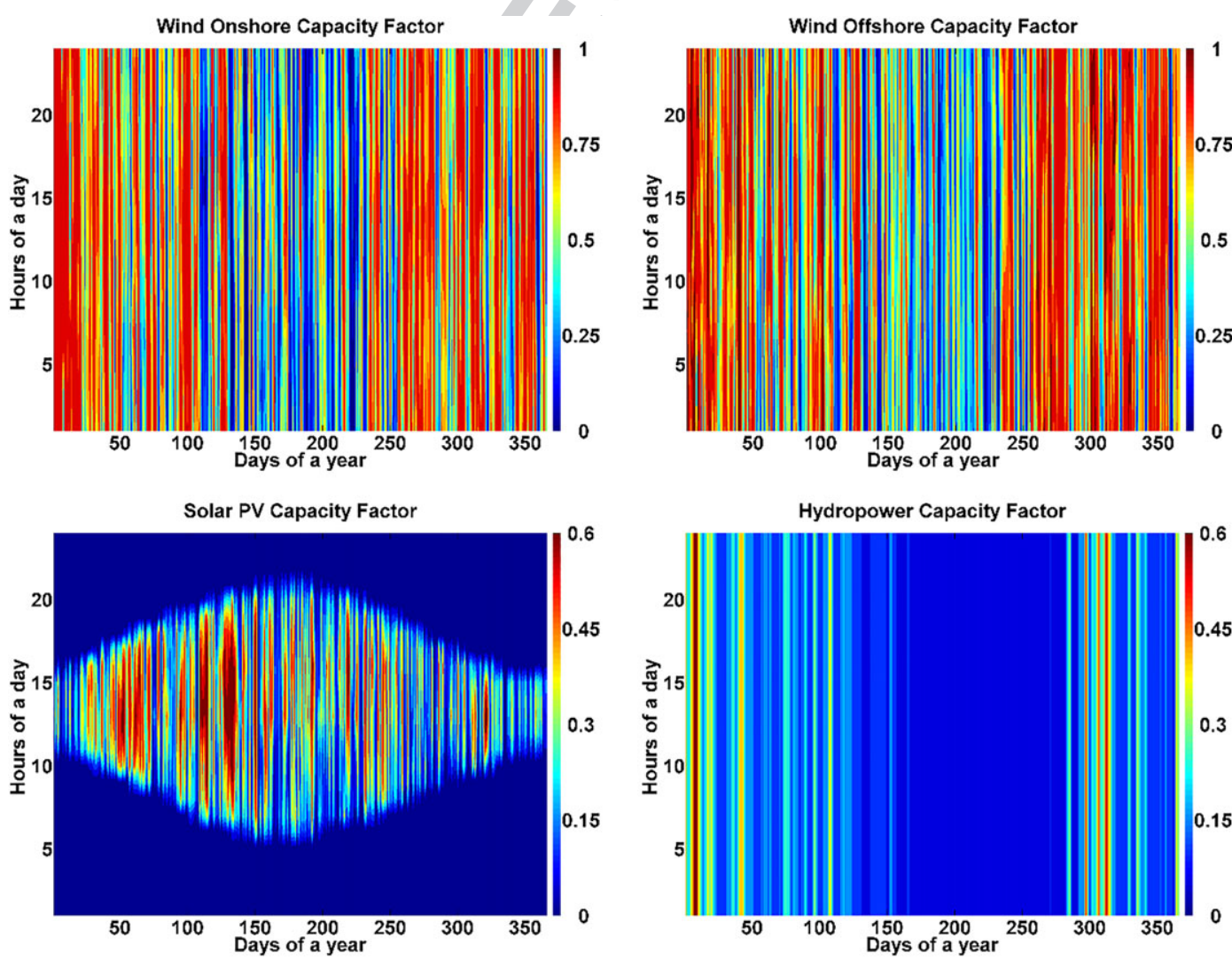

FIGURE 6 Hourly resolved capacity factors for wind onshore (upper left), wind offshore (upper right), solar PV (lower left), and hydropower (lower right) electricity production [Colour figure can be viewed at wileyonlinelibrary.com] 

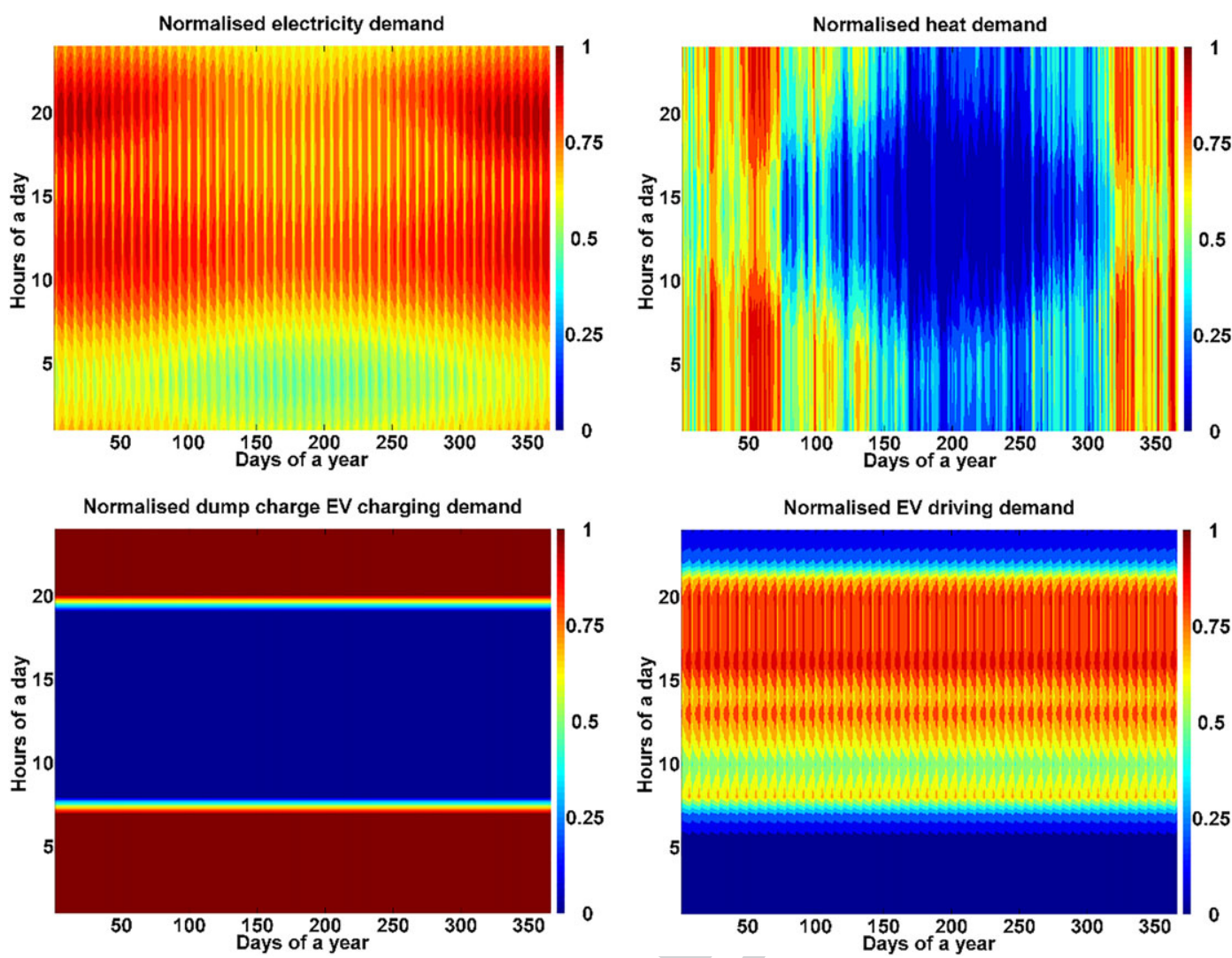

FIGURE 7 Normalized electricity demand (upper left) and normalized heat demand (upper right). Electricity charging for dump-charge vehicles occurs during night hours (lower left), while discharge for all electric vehicles occurs primarily during the day (lower right) [Colour figure can be viewed at wileyonlinelibrary.com]

$75 \mathrm{MW} / \mathrm{km}^{2}$ for solar PV, ${ }^{49}$ the highest land use for onshore wind would be in the 2030 Hinkley scenario, at $2.0 \%$ of area (1548 $\left.\mathrm{km}^{2}\right)$. It is assumed that much of this area could still be used for other purposes, particularly agriculture. The highest land use for solar PV would be in the $2050100 \%$ RE scenario, at $0.2 \%$ of area $\left(134 \mathrm{~km}^{2}\right.$ ). It is assumed that much of this area could be dedicated to rooftops or other negative impact areas. Hydropower generation capacity factors are based on the same weather year as wind and solar power. ${ }^{52}$

\subsection{2 | Load data}

Several important hourly profiles were used to represent basic electricity demand, heat demand, and electricity demand for transport. These distributions are shown in Figure 7. The hourly electricity demand profile was derived from Child et al ${ }^{53}$ for the UK as a whole. A synthetic heat demand profile was generated for Scotland and is shown in Figure 7 (upper right). Electric vehicle charging and driving distributions were taken from the EnergyPLAN database. ${ }^{26}$ As EnergyPLAN requires hourly data for 8784 hours of the year, data available for December 31 were repeated once to complete the yearly distribution when necessary. Most models and data source choose a standard year of 8760 hours, so an extra day of data needed to be created to conform to the data requirements of EnergyPLAN. These distributions are also shown in Figure 7.

\subsection{3 | Cost assumptions}

For all financial calculations, a weighted average cost of capital (WACC) of 7\% is assumed. For most technologies, investment costs, and operations and maintenance costs are taken from the EnergyPLAN cost database $3 .{ }^{48}$ and are expressed in 2018 values. These costs have been modified for other technologies, such as solar PV, to reflect different costs for rooftop and ground-mounted systems, and for all aspects of power-to-gas (PtG) technology. Separate cost assumptions have been made for three different rooftop market segments (household, commercial, industrial) and for large-scale ground-mounted systems. Utility solar costs are assumed to reduce by $75 \%$ between 2015 and 2050 . The latest international cost trends indicate that large-scale, international utility solar power plants have already achieved about $40 \%$ of this reduction by autumn 2018 (to 652 USD/ $/ W_{\mathrm{p}}$, or approximately $567 € / \mathrm{kW}_{\mathrm{p}}$ ), as a consequence of very high learning rates close to $40 \%$, very fast market expansion in recent years and outstandingly high competition. ${ }^{54}$ This latest market figure indicates the applied cost assumptions are rather conservative. PtG costs have been assumed based on 2030 assumptions from Fasihi et al. ${ }^{55}$ A detailed list of all cost assumptions can be found in the Supporting Information. 


\section{3 | RESULTS}

Fuel and resource consumption for the different scenarios is shown in Figure 8. In addition, energy flow diagrams from primary energy sources to $\mathbf{F 8}$ end-user consumption are illustrated in Figures 12 and 13 for the 2015 and 2050 100\% RE scenarios, and for all scenarios in the Supporting Infor- F12 F13 mation. Primary energy demand is significantly lower in future scenarios, ranging from 146 to 202 TWh, in contrast to 246 TWh in the 2015 scenario. Highest primary energy demand is in the 2030 Hinkley scenario and the lowest in the $205075 \%$ RE scenario.

Figure 9 shows final energy consumption for each scenario. In 2015, scenario final energy consumption is 157 TWh and efficiency improve- F9 ments in all sectors result in a slight reduction in future scenarios. Lowest final energy consumption of 128 TWh is seen in the $2050100 \%$ RE scenario. Figures 8 and 9 show that rather stable, or slightly reduced final energy consumption can be achieved at much lower levels of fuel consumption and primary energy demand.

Electricity generation by different technologies for each scenario is shown in Figure 10, followed by corresponding electricity consumption in F10 Figure 11. Electricity consumption in all 2030 and 2050 scenarios increases significantly from 51 TWh in 2015. This is due to increased electrifi- F11 cation and defossilization of the heat and transport sectors. In future scenarios, electricity consumption ranges from 80 to 141 TWh, with the

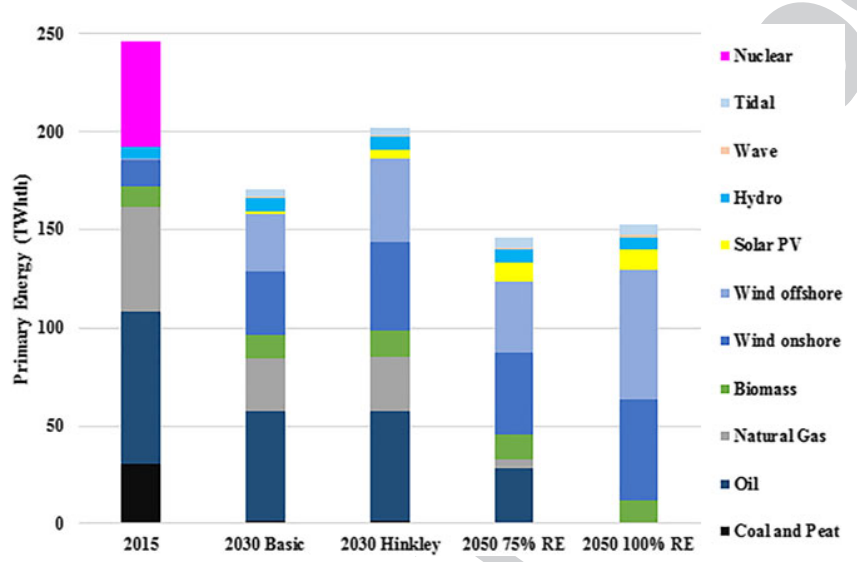

FIGURE 8 Fuel and resource consumption for all scenarios [Colour figure can be viewed at wileyonlinelibrary.com]

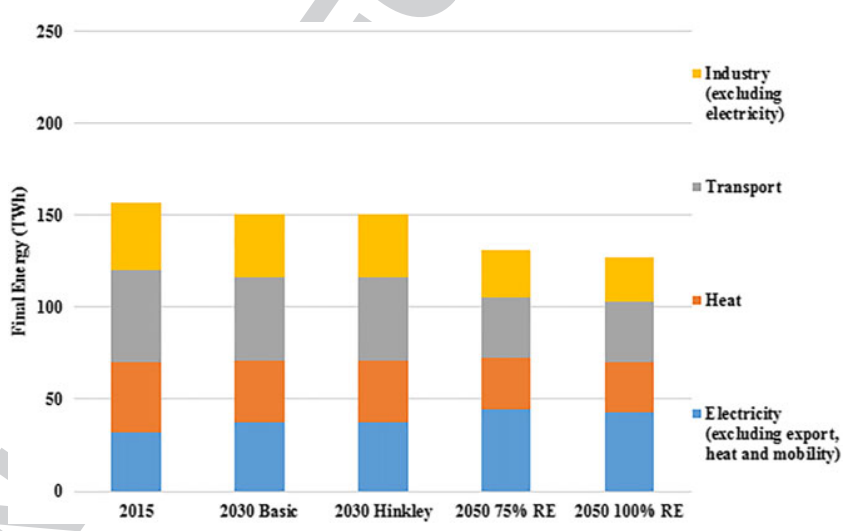

FIGURE 9 Final energy demand for all scenarios [Colour figure can be viewed at wileyonlinelibrary.com]

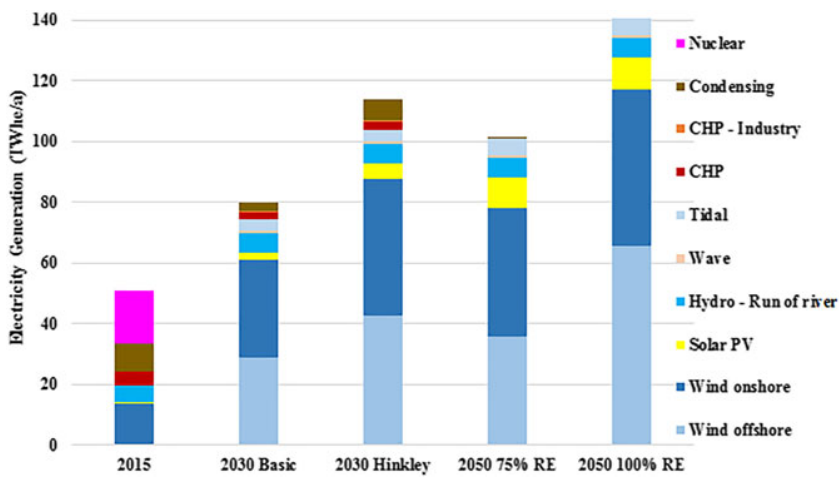

FIGURE 10 Electricity production for all scenarios [Colour figure can be viewed at wileyonlinelibrary.com] 


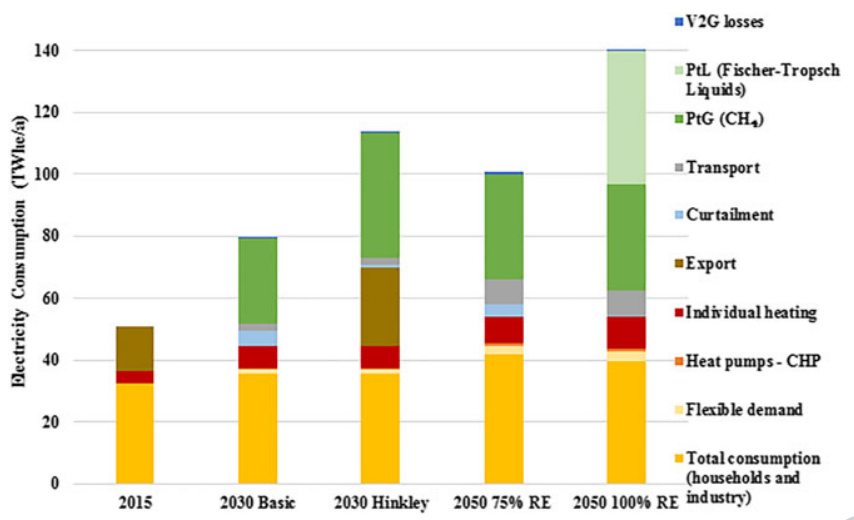

FIGURE 11 Electricity consumption for all scenarios [Colour figure can be viewed at wileyonlinelibrary.com]

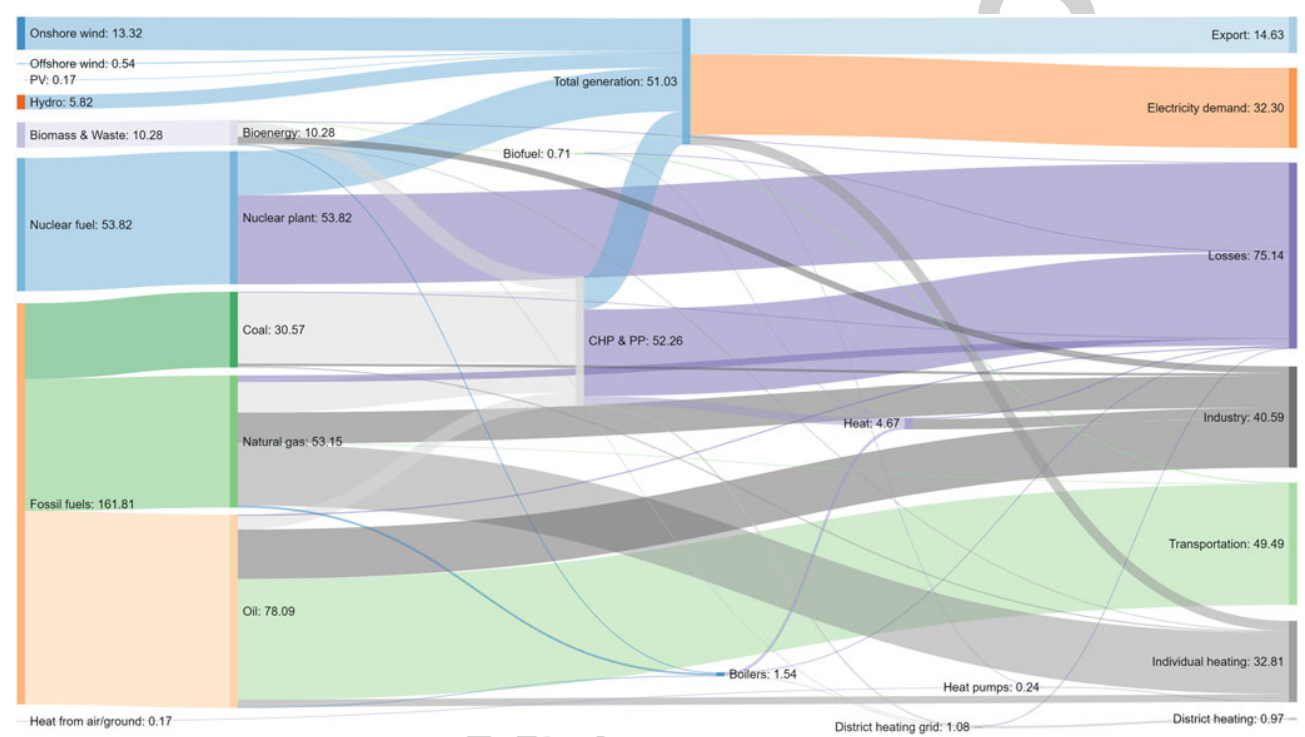

FIGURE 12 Energy flows for the 2015 scenario [Colour figure can be viewed at wileyonlinelibrary.com]

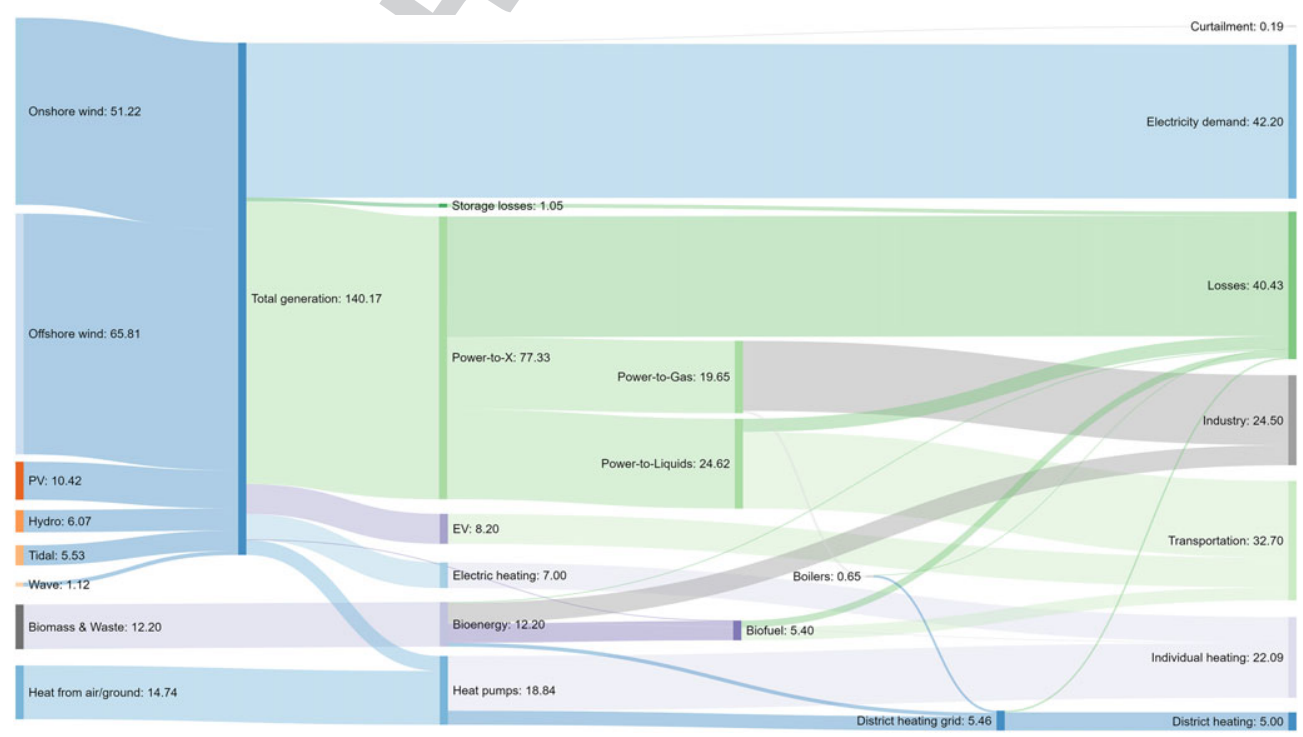

FIGURE 13 Energy flows for the 2050 100\% RE scenario [Colour figure can be viewed at wileyonlinelibrary.com]

highest value seen in the 2050 100\% RE scenario. In the 2015 scenario, 15 TWh of electricity is exported. In the 2030 Hinkley scenario, 25.3 TWh is exported, equal to the assumed annual baseload generation of the Hinkley Point $C$ nuclear power plant. No electricity import or export was allowed in other scenarios. 
Electricity generation in 2030 and 2050 increases correspondingly to increased electricity consumption. Onshore and offshore wind are the technologies with the highest generation in future scenarios, and their generation ranges from $61 \mathrm{TWh}$ in the 2030 Basic scenario to $117 \mathrm{TWh}$ in the 2050 100\% RE scenario. Simultaneously, generation from thermal power plants decreases from 31 TWh in 2015 to virtually zero in the 2050 $100 \%$ RE scenario. Higher electricity consumption in the $2050100 \%$ RE scenario in comparison to the $75 \%$ RE scenario is mostly due to power-toliquid fuel production, which is needed to defossilize heavy transport.

Figures 12 and 13 show energy flow diagrams for the 2015 and 2050 100\% RE scenarios. Other scenario energy flow diagrams are presented in the Supporting Information. Results show that defossilization occurs through efficiency gains made related to overall final demand reductions in the heating, transport, and industry sectors, as well as from the electrification of more energy services across all sectors.

Total annualized costs divided into different categories for each scenario are shown in Figure 14. In 2050, the lowest annual cost is F14 achieved in the $100 \%$ renewable energy system, and the annual cost of such a system is also 1 b€ lower than in the 2015 scenario. Generating a renewable 25.3 TWh of baseload electricity in Scotland is $330 \mathrm{M€} / \mathrm{a}$ cheaper than the subsidized generation cost of an equal amount of electricity from the proposed Hinkley Point C nuclear power plant. The total annualized cost for the 2030 Basic scenario is 16.214 b€/a, including $2.834 \mathrm{~b} € / \mathrm{a}$ for subsidized electricity for Hinkley Point C. For the 2030 Hinkley scenario, the total annualized cost is 15.884 b€/a, including $326 \mathrm{m€} / \mathrm{a}$ for a new transmission interconnection of $3200 \mathrm{MW}$. This means that the cost of electricity generation for the exported electricity equivalent to the 25.3 TWh expected from Hinkley Point C is 2.178 b€/a (excluding transmission costs), which is $23 \%$ lower than the expected subsidized price. This figure is perhaps more relevant as a $4200 \mathrm{MW}$ transmission interconnection already exists between Scotland and the UK. In scenarios with higher shares of renewables, the relative shares of operation, $\mathrm{CO}_{2}$, and fuel costs are lower, while the share of investment costs is higher.

An estimate of job creation was performed based on the installed capacities of solar PV and wind energy for each year based on IRENA estimates for OECD countries. ${ }^{56}$ Accordingly, 8.6, 18.1, and 17.9 full time equivalent (FTE) manufacturing, construction, and installation (MCI) job-years are created for each MW of onshore wind, offshore wind, and solar PV installed, respectively. Furthermore, $0.2,0.2$, and 0.3 permanent operations and maintenance (O\&M) jobs are created over the lifetime of each respective technology. It was assumed that $60 \%$ of $\mathrm{MCl}$ jobs and $50 \%$ of O\&M jobs could be domestic. No accounting of job creation related to synthetic fuel production, V2G services, or plant decommissioning was performed due to the lack of reliable job estimates. For this reason, the estimates shown in Table 4 could be seen as lower limits for job T4 creation. Highest values are seen in the 2030 Hinkley and 2050 100\% RE scenarios.

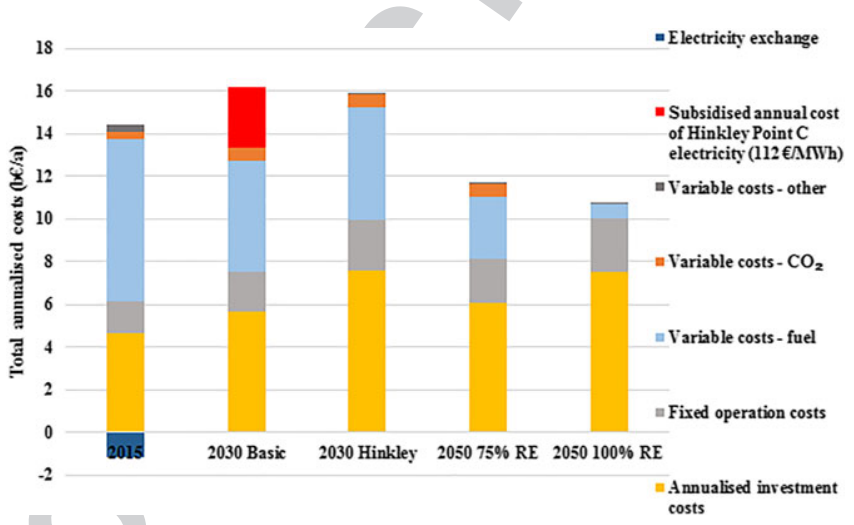

FIGURE 14 Total annualized costs for all scenarios [Colour figure can be viewed at wileyonlinelibrary.com]

TABLE 4 Job creation estimates (in job-years) for all scenarios

\begin{tabular}{|c|c|c|c|c|c|}
\hline & 2015 & 2030 Basic & 2030 Hinkley & $\begin{array}{l}2050 \\
75 \% \text { RE }\end{array}$ & $\begin{array}{l}2050 \\
100 \% \text { RE }\end{array}$ \\
\hline Wind onshore & 46087 & 81700 & 111800 & 81700 & 98900 \\
\hline Solar PV & 3938 & 44750 & 107400 & 170050 & 179895 \\
\hline $\mathrm{MCl}$ Total & 53410 & 235050 & 378480 & 369400 & 495995 \\
\hline Wind onshore & 1072 & 1900 & 2600 & 1900 & 2300 \\
\hline Solar PV & 66 & 750 & 1800 & 2850 & 3015 \\
\hline O\&M total & 1175 & 3850 & 6160 & 6050 & 7715 \\
\hline Domestic $\mathrm{MCl}$ & 32046 & 141030 & 227088 & 221640 & 297597 \\
\hline Domestic O\&M & 588 & 1925 & 3080 & 3025 & 3858 \\
\hline Domestic job-years & 32634 & 142955 & 230168 & 224665 & 301455 \\
\hline
\end{tabular}


Table 5 presents GHG emission amounts and costs, along with the share of RE in each scenario. GHG emissions are essentially zero in the T5 $100 \%$ RE scenario for 2050. Remaining emissions in that scenario are associated with the non-biogenic portion of waste combustion.

\section{4 | DISCUSSION}

\subsection{The costs of energy in Scotland}

Over the short term, it appears that the vast renewable resource potential of Scotland can be harnessed to provide a more robust, resilient, and sustainable solution to the contentious issue of the Hinkley Point C nuclear power plant development. Despite the fact that the UK has endorsed nuclear power development as a mitigation strategy for climate change, Scotland has consistently rejected new nuclear development. ${ }^{9}$ Therefore, a potentially disruptive political issue within the UK could be avoided through increased RE development in Scotland that could provide baseload power equivalent to a large nuclear power plant to the rest of the UK. Results of this analysis show that Scottish RE, primarily wind power, could be harnessed to supply the 25.3 TWh of baseload power from Hinkley Point $\mathrm{C}$ at a lower cost ( $99 € / \mathrm{MWh}$ ) than the expected subsidized price of $112 € / M W h(92.50 \mathrm{f} / \mathrm{MWh}$ in 2013). This represents a $12 \%$ savings for UK taxpayers, or approximately 330 m€ annually, given the assumptions used in this study. When neglecting the cost of transmission between Scotland and the rest of the UK ( 326 m€/a), savings on electricity generation costs are $23 \%$. This is a notable observation given that sufficient transmission interconnection already exists. Cost savings could be calculated as even greater given that the subsidized price for Hinkley Point C power will be linked to Consumer Price Inflation, and that total inflation between 2013 and 2018 of approximately 7.9\% in the UK has increased the price to almost $101 \mathrm{f} / \mathrm{MWh}$. When calculated using the long-term average exchange rate of $1.32 € / €$, the result is a price of $133 € / \mathrm{MWh}(26 \%$ savings). However, using a current exchange rate of $1.15 € / £$, the price is $116 € / M W h(15 \%$ savings). Further to these cost savings, the substitution of Scottish renewable energy for nuclear power represents much lower societal risk. ${ }^{57-59}$ It is, however, unclear the extent to which "the dreadful deal behind the world's most expensive power plant"60 can be amended or undone.

Over the long term, higher shares of renewable energy in the Scottish energy system appear to result in lower overall costs. In the 2050 scenarios, this is achieved through significant reductions in fuel and emissions costs despite noticeably higher investment and fixed operational costs (Figure 14). Total annualized costs for the 2050 100\% RE scenario are 10.7 b€/a, compared to 11.7 b€/a for the $205075 \%$ RE scenario, a savings of approximately $8 \%$. This result is in line with several similar EnergyPLAN studies of integrated energy systems that show that $100 \%$ RE scenarios are lower in cost than alternatives with fossil fuels. ${ }^{30-32}$ Other EnergyPLAN simulations show that scenarios with $100 \%$ RE are only marginally higher in cost than those featuring fossil fuels. ${ }^{28,29,31,61}$ However, these latter studies have employed rather conservative cost estimations for many technologies, especially solar PV and wind power. Cost assumptions used in this current work more accurately reflect the cost trends that have occurred with RE technologies in recent years, and that are expected for the future. ${ }^{11}$ Over the period of 2009 to 2017 , the levelized cost of solar PV decreased by $72 \%$, and onshore wind power by $27 \%$, while the cost of offshore wind power fell $44 \%$ since $2012 .{ }^{62}$

\section{2 | Other economic benefits}

The positive economic impacts of Scottish investment in RE, outside of strict energy system costs, must also be considered. This analysis shows that the 2050 100\% RE scenario would result in roughly $25 \%$ more employment as measured in job-years than the $205075 \%$ RE scenario (300 359 and 224665 job-years, respectively). This result is in line with several studies that show a positive link between RE and job creation. ${ }^{28,29,56,63,64}$ Furthermore, there may also be positive employment effects for renewable energy and storage. ${ }^{11,19}$ These results are also similar to expectations of the Scottish Government that the transition towards sustainability "will attract investment and stimulate the growth of highly skilled employment, benefiting people in both rural and urban areas of Scotland."

\section{3 | Carbon capture and storage}

In addition, a $100 \%$ RE system could be the only way to meet the ambitious targets set out in the Paris Agreement, and to ensure a sustainable and resilient energy system. Fossil fuel use, fossil-based CCS, and nuclear power fail to address a wide range of sustainability criteria and do little to safeguard critical planetary boundaries. ${ }^{6}$ Moreover, negative emissions schemes, such as CCS may not be effective in respecting the

TABLE 5 GHG emissions, their costs, and share of renewables for all scenarios

\begin{tabular}{|c|c|c|c|c|c|}
\hline & & 2030 & 2030 & 2050 & 2050 \\
\hline Parameter & 2015 & Basic & Hinkley & $75 \% \mathrm{RE}$ & $100 \%$ RE \\
\hline $\mathrm{CO}_{2}$-equivalent $\mathrm{GHG}$ emissions (Mt) & 42.13 & 21.1 & 21.25 & 8.59 & 0.11 \\
\hline Cost of GHG emissions (MEUR) & 337 & 633 & 638 & 644 & 8 \\
\hline Renewables share of primary energy (\%) & 12 & 50 & 58 & 78 & 100 \\
\hline
\end{tabular}


2 degree, Paris Agreement target. ${ }^{65,66}$ They also leave future generations with the burden of maintaining constant vigilance to prevent catastrophic leakage, an arrangement that has been described as a "Faustian Bargain par excellence." ${ }^{67}$ Further, leakage may occur upstream from fuel use in power plants, CCS can reduce the efficiency of a power plant and create the need for more fuel use, and capture efficiency is typically only $50 \%$ to $90 \%{ }^{68,69}$ The result of all this is net emissions, which is in contradiction to the 2 degree target. Finally, gas-based and coal-based CCS in the UK are expected to result in the high levelized costs of electricity, approximately 112 and $126 € /$ MWh, respectively. ${ }^{41}$ All of this casts doubt on the viability of some negative emissions schemes, leaving some to ponder if "CCS may be, politically, an easy way out of having to make more difficult and sustainable choices." ${ }^{17}$ At the same time, other negative emissions schemes, such as direct air carbon capture and storage (DACCS), bioenergy enhanced carbon capture and storage (BECCS), enhanced weathering (EW), afforestation and reforestation (AR), and soil carbon sequestration (SCS) may represent less overall risk, and Scotland may be well suited for such net emissions technologies. ${ }^{70}$

The results of this study show that Scotland can achieve both the 80\% GHG emissions reduction target and the more ambitious net zero emissions target without dependence on CCS. The 2050 75\% RE scenario shows how this can be achieved at the $80 \%$ reduction level. Further, achieving essentially zero emissions at a lower overall cost was shown in the $2050100 \%$ RE scenario. Achieving negative emissions in Scotland appears possible given the reported attractiveness of negative emissions schemes not involving fossil fuels. Further study is needed to determine the economic feasibility of such schemes, and whether this would be a desirable development for the people of Scotland.

\section{4 | Elements of the energy system}

In the $2050,100 \%$ RE scenario, wind energy dominates the energy system, representing $77 \%$ of primary energy and $83 \%$ of electricity generation. Solar PV represents just over $7 \%$ of electricity, while wave and tidal energy contribute $5 \%$. Hydropower contributes the final $5 \%$. In this manner, electricity generation becomes more diverse, thereby offering greater resilience to the system. Wind energy is split between $44 \%$ onshore and $56 \%$ offshore turbines. At the same time, there is an opportunity to take advantage of the many islands and archipelago located in Scottish waters. Other studies have noticed that such small island-based wind energy production offers a combination of reduced onshore turbine installation costs and increased offshore wind quality. ${ }^{31}$ The results of this study show ${ }^{71}$ that not only can Scottish renewable resources satisfy the demands for energy domestically but also indicate that they may be valuable for the UK as a whole. Further study is needed to show if such resources could be of benefit on an even larger scale.

To achieve such high shares of RE, energy storage and flexibility measures are necessary. It is generally accepted that storage will be necessary after the share of RE reaches $50 \%$ of electricity generation, and that long-term, seasonal storage will be necessary once the share of RE is greater than $80 \%{ }^{72,73}$ In the $2050,100 \%$ RE scenario, short-term storage is provided by $220 \mathrm{GWh}$ of V2G batteries and 85 GWh of pumped hydro storage (PHS). Longer term storage is handled by $10 \mathrm{GWh}$ of thermal storage for district heating and $6500 \mathrm{GWh}$ of grid gas storage. No stationary battery storage was utilized in this scenario, as the other storage technologies were sufficient. V2G batteries averaged only 100 full charge cycles per year, while PHS averaged just over 5 full charge cycles per year. It was noticed that in neither 2050 scenario were the full potentials of the V2G connections exploited. Despite a charge power of $25 \mathrm{GW}$ in each scenario, only 15.5 and $17.5 \mathrm{GW}$ were the maximum values for the $75 \%$ RE and $100 \%$ RE scenarios, respectively. This suggests that while V2G batteries are an important source of flexibility for the energy system, they may not necessarily be overburdened by usage.

\subsection{Harnessing flexibility and efficiency}

As part of the long-term storage and flexibility, both power-to-liquids and PtG played significant roles. These technologies were especially important in handling the more rigorous demands of the transport and industry sectors. In the areas of the transport sector that were not entirely suitable for electrification (eg, heavy-duty trucking, shipping and aviation), liquid fuels were supplied in the $100 \%$ RE scenario partly from bioenergy sources (3.5 TWh), but mostly from synthetic fuels (21 TWh) derived from the combination of renewable electricity, electrolysis, DAC of $\mathrm{CO}_{2}$, and Fischer-Tropsch synthesis. Ridjan et al ${ }^{74}$ emphasized the need to have a variety of transport fuel solutions in order to respect the natural limits of biomass resources. And synthetic fuels have been identified as a cost competitive way to achieve net zero emissions. ${ }^{55}$ This research lists several advantages to synthetic fuels based on renewable electricity and $\mathrm{CO}_{2}$ utilization/recycling, such as adding another layer flexibility to the energy system, using electrolysers to help to balance grids, and facilitating the integration of wind power, such as seen in the current study. At the same time, Garcia-Olivares ${ }^{75}$ cautions that the overall efficiency of the power-to-synthetic fuel process can be as low as $24 \%$, and questions whether the use of gaseous fuels (eg, hydrogen or synthetic methane) might be preferable to synthetic liquid fuels. It must be acknowledged that if transport solutions were widely developed to use gaseous fuels, this would most certainly be a more energy efficient solution, as also found by Horvath et $a^{76}$ for the case of the marine transport. However, this current study aimed to produce fuels that were known to work with already existing transport technologies (eg, jet engines that combust kerosene). Connolly et al ${ }^{77}$ also state gaseous fuels may be the most efficient means to supply certain types of heavy-duty transport but acknowledge the expense of both vehicle and infrastructure development needed to utilize such fuels. It remains an interesting area of future study to determine which would be preferable in the end: 
synthetic liquid fuels that could be "dropped in" to existing technologies and infrastructure without the possibly expensive need for technology and infrastructure replacement, or renewable-based gaseous fuels that could be used with newly developed technologies.

Products of the PtG process are seen in each of the future scenarios, to varying degrees. Figure 11 shows that similar amounts of electricity are used in each future scenario to produce synthetic methane, which can be flexibly used in the industrial, heating, and power sectors. In the 2030 Hinkley scenario, slightly more dispatchable synthetic methane is produced in order to facilitate the increased electricity demand and higher share of electricity production in gas-based thermal power plants (see Figure 10). The potential benefits of the PtG process are supported widely in scientific literature $\left(\mathrm{eg}^{29,49,78-81}\right)$. The PtG process is based on known technology, and profitable business cases have already appeared. ${ }^{82}$ Although a number of technical and economic barriers have been associated with PtG, it has been shown that it can become an effective and cost competitive solution for the future. ${ }^{83,84}$ The flexibility it offers extends into seasonal use of the storable synthetic gas for later dispatchable use in a variety of processes. In addition, flexible use of electrolysers to create the hydrogen needed in the PtG process can aid in grid balancing, as noted above. Of note is that Scotland already possesses a substantial gas infrastructure, with more than 1.8 million consumers served by approximately $25000 \mathrm{~km}$ of gas pipelines. ${ }^{85}$ Further, the operations of Scotland Gas Networks extend throughout the UK, serving 5.9 million customers with $71000 \mathrm{~km}$ of pipelines in total. ${ }^{86} \mathrm{In}$ a PtG scenario, this means that past investments in modern gas-based infrastructure will not be stranded. As well, employment, knowledge and skill developed by the current gas industry in Scotland can remain a domestic strength.

Flexibility is also seen on the supply side. The variable generation from wind and solar PV would be complemented by highly flexible energy supply from combustion of solid fuels such as waste and solid biomass residues, and of gaseous fuels, such as biogas, biomethane, and synthetic natural gas. This flexibility would ensure balance and stability of grids, and that demands can be met for every hour of the year in all sectors. The complementarity of various forms of flexible generation, energy storage, and sector integration suggested here has been shown to reduce the need for overall backup capacity and help maintain more regular use of existing generation capacity. ${ }^{87}$ Further, the power-to-heat supply suggested here (composed of electric boilers, heat pumps, and thermal energy storage) has been shown to improve flexibility in large-scale variable renewable power systems. ${ }^{88,89}$

An important source of efficiency gain through electrification, energy storage, and flexibility can be seen with electric vehicles. As part of a Scottish Government future scenario (An Electric Future), all passenger and light-duty transport are targeted to be powered by electricity. ${ }^{9}$ In the current study, the same assumption was made for 2050, with the balance of transport demand (heavy trucking, ships, air travel) being satisfied by biofuels and fossil fuels in the $205075 \%$ RE scenario, and by biofuels and synthetic fuels derived from renewable electricity in the $2050100 \%$ RE scenario. For passenger and light duty vehicles, efficiency gains through electrification represent an almost $300 \%$ improvement, with driving distance assumed to increase by a factor of 4 from 1.24 passenger kilometres (pkm) per kWh for internal combustion engines to $5 \mathrm{pkm} / \mathrm{kWh}$ for electric vehicles. Further, the assumed $220 \mathrm{GWh}$ of available battery storage could serve two purposes. First, smart charging of roughly $80 \%$ of vehicles could result in increased flexibility of the energy system at times of high generation from VRE. In this way, the batteries represent a temporal buffer between electricity generation and driving demand. Second, V2G participation could result in high amounts of electricity being available at times when VRE generation is low. Charging of V2G batteries represented 20.5 TWh in the $205075 \%$ RE and 22.0 TWh in the $2050100 \%$ RE scenarios, with 13.2 and 14.7 TWh returning back to the grid in each scenario, respectively. In the $2050100 \%$ RE scenario, this represents $10 \%$ of electricity generation.

As suggested by Child et al, ${ }^{31}$ participation in V2G services offers several advantages to individuals and to the energy system as a whole. Firstly, Zhang et $\mathrm{al}^{90}$ showed that both vehicle owners and grid operators can achieve lower costs by optimizing charging of BEVs through response to pricing schemes known a day in advance. Second, transmission line losses and other grid operation costs could be reduced through the utilization of grid interactive BEVs and strategic energy management. ${ }^{91}$ Third, Kiviluoma ${ }^{92}$ suggests that smart charging of BEVs can reduce power system costs by around $227 € /$ vehicle annually. Lastly, it has been demonstrated that high BEV penetration in the transport sector can provide additional electric storage that can be of benefit to managing high shares of VRE. ${ }^{93}$

Energy efficiency gains are also seen in both the built environment and industry. In the 2050 scenarios, the more broad use of heat pumps and electrification of energy services across all energy sectors results in lower overall demands for the heating and industry sectors (Figure 9) despite a noticeable increase in electricity demand. The results of this analysis are compatible with targets set for residential heating described online. ${ }^{9}$ However, the 2050 100\% RE scenario proposes more radical change in the transport and industrial sectors. First, this scenario proposes that both sectors can be completely defossilized. In the transport sector, this is achieved partly through the broad use of electric vehicles and biofuels, which is consistent with Scottish visions. However, the $100 \%$ RE scenario proposes that much of heavy transport, shipping, and aviation can be supplied by synthetic transport fuels, such as synthetic diesel and kerosene, through Fischer-Tropsch conversion. By comparison, the 75\% RE scenario proposes no synthetic fuels use but instead uses fossil fuels in these areas of transport. Likewise, the $100 \%$ RE scenario shows no use of fossil fuels in industry, while the $75 \%$ RE scenario shows limited use of oil and natural gas in Scottish industry. Given that both oil and natural gas are domestic resources in Scotland, 2050 scenarios designed by the Scottish Government all show the use of these resources in the transport and industry sectors. ${ }^{9}$ It is the stated aim of the Scottish government to "support investment, innovation and diversification across our oil and gas sector." ${ }^{9}$ However, it must be remembered that much of the knowledge of the oil and gas industry is based on hydrocarbon chemistry, something that can also be valuable in the creation of synthetic fuels, which is nothing more than hydrocarbon chemistry. Therefore, switching focus away from fossil fuels to synthetic fuels need not represent a significant departure from existing Scottish skills and knowledge. For the same reason, job losses in the oil and gas industry may not necessarily be dramatic. Diversification, innovation, and investment can be encouraged in relation to synthetic fuel production. 


\subsection{Climate action throughout society}

The Scottish Government also wishes to encourage climate action amongst private citizens. The EnergyPLAN results show how private citizens can contribute in several ways. First, participation in V2G services has been shown to reduce the need for additional generation and storage capacity in energy systems, resulting in significant overall cost savings. ${ }^{31,32}$ In the $2050100 \%$ RE scenario, the role of V2G was moderate, yet important in maintaining the delicate balance between electricity supply and demand. Second, flexible demands by end-users of electricity were also enabled in this scenario. Approximately $8 \%$ of end-user electricity demand was deemed flexible, to a total of 4.6 TWh per year. In this case, there was 3 TWh per year of demand response, whereby a total of $1500 \mathrm{MW}$ of power could be flexible in any given hour, which represented about $22 \%$ of peak power demand. To this was added 1.6 TWh of so-called dump charge electric vehicle charging. EnergyPLAN also considers this part of flexible electricity use, as the majority of this charging would occur in off-peak times during the night. Over the year, flexibility represented an average power transfer of $524 \mathrm{MW}$ ( $8 \%$ of peak demand), and the maximum hourly value for the year was $1864 \mathrm{MW}$ ( $28 \%$ of peak demand).

Second, it was assumed that Scottish citizens would participate in more distributed energy generation and prosumerism. In the 2050 scenarios, solar PV would be installed on the rooftops of residential, commercial, and industrial buildings. This would represent $60 \%$ of the total installed capacity of $10 \mathrm{GW}$ of solar PV throughout the country. In addition, the residential and commercial space heating sector would undergo transformation. The fossil fuel-based heating system (based mostly on natural gas) would be replaced by one based primarily on electricity, with the more widespread adoption of heat pumps. In the 2050 100\% RE scenario, it was shown that $81 \%$ of space heating demand could be met by heat pumps and direct electric heating. This assumption was consistent with the goal of $80 \%$ set for the "An Electric Future" scenario of the Scottish Government. ${ }^{9}$ Societal participation would also involve implementing many of the efficiency gains mentioned above. In all, participation in climate action and achieving greater sustainability would need to involve all sectors of society.

\section{5 | CONCLUSION}

Based on the assumptions used, this study concludes that the richness of Scottish renewable energy resources can aid in achieving full defossilization of the energy system by 2050 in an economically and technologically feasible manner. Furthermore, the $100 \%$ renewable energy system proposed in this study offers a higher level of system resilience and sustainability than any previous study of the Scottish energy system, as well as one consistent with the ambitious targets of the Paris Agreement. The $100 \%$ renewable energy scenario proposed in this work is also consistent with the targets of the Scottish Government to be amongst the world's leaders in climate action across all sectors of society. Defossilization can be achieved without reliance on CCS technology, which represents unnecessary cost and risk to society. A combination of flexible generation from a range of renewable energy resources, including wind, solar PV, tidal, wave, hydropower, and biomass-based energy, as well as the use of energy storage technologies such as BEV batteries, pumped hydro storage, thermal energy storage, gas storage, PtG, and power-to-liquids technologies can assure the reliability of the energy system for each hour of the year.

Furthermore, Scottish renewable energy could be used at lower overall cost and societal risk to replace the baseload generation expected from the proposed and controversial Hinkley Point C nuclear power plant. This study shows that Scotland could offer the rest of the UK up to $23 \%$ savings on electricity generation cost in 2030 compared to the proposed subsidized price of $112 € /$ MWh for electricity generated from Hinkley Point C. Primarily, this energy can be derived from Scottish wind resources, both onshore and offshore, which are amongst the best wind resources in the world. This study confirms that decreases in the costs of renewable energy and storage technologies have reached a critical level that make new investments in nuclear power questionable. Further public discourse on the future of energy in Scotland and the UK as a whole seems warranted.

\section{ORCID}

Michael Child (10) https://orcid.org/0000-0003-1240-1445

\section{REFERENCES}

1. UNFCCC Conference of the Parties. Adoption of the Paris Agreement. Proposal by the President. New York; 2015. doi: FCCC/CP/2015/L.9/Rev.1. http:// unfccc.int/resource/docs/2015/cop21/eng/I09r01.pdf. Accessed: March 23, 2018.

2. Edenhofer O, Pichs-Madruga R, Sokona Y, et al. Summary for Policymakers. In: Climate Change 2014: Mitigation of Climate Change. Contribution of Working Group III to the Fifth Assessment Report of the Intergovernmental Panel on Climate Change. Cambridge, United Kingdom and New York: Cambridge University Press; 2014.

3. O'Brien K, Hayward B, Berkes F. Rethinking social contracts: building resilience in a changing climate. Ecol Soc. 2009;14(2):47-59. https://doi.org/ $10.1177 / 003231870806000105$

4. Rockström J, Steffen W, Noone K, et al. Planetary boundaries: exploring the safe operating space for humanity. Ecol Soc. 2009;14(2).

5. Steffen W, Richardson K, Rockström J, et al. Planetary boundaries: guiding human development on a changing planet. Science. 2015;347(6223). https:// doi.org/10.1126/science.1259855, 1259855

6. Child M, Koskinen O, Linnanen L, Breyer C. Sustainability guardrails for energy scenarios of the global energy transition. Renew Sustain Energy Rev. 2018;91:321-334. https://doi.org/10.1016/j.rser.2018.03.079

7. Scottish Government. Climate Change Plan. Edinburgh; 2018 http://www.gov.scot/Publications/2018/02/8867/downloads. Accessed March 24, 2018. Q3 
8. Brooks L. Scotland draft climate change bill sets $90 \%$-by-2050 emission reduction target. The Guardian International Edition. https://www.theguardian. com/environment/2018/may/24/scotland-draft-climate-change-bill. Published 2018. Accessed March 15, 2018

9. Scottish Government. Scottish Energy Strategy: The Future of Energy in Scotland. Edinburgh; 2017 http://www.gov.scot/Publications/2017/12/5661. Accessed March 24, 2018.

10. Vaughan A. Cracks in nuclear reactor will hit EDF Energy with $£ 120 \mathrm{~m}$ bill. The Guardian International Edition. https://www.theguardian.com/environment/2018/may/06/cracks-nuclear-reactor-threaten-uk-energy-policy-hunsterston. Published 2018.

11. Ram M, Child M, Aghahosseini A, Bogdanov D, Poleva A. Comparing Electricity Production Costs of Renewables to Fossil and Nuclear Power Plants in G20 Countries. Hamburg; 2017. http://bit.ly/2u28uOL. Accessed May 9, 2018.

12. Goldthorpe W, Ahmad S. The "market" is failing CCS. Pan Eur Networks Gov 2015:124-126. http://horizon2020projects.com/wp-content/uploads/ 2013/12/GOV14-Crown-Estate_P12107-pro.pdf. Accessed May 7, 2018.

13. Science Advice for Policy by European Academies. Novel Carbon Capture and Utilisation Technologies. Berlin; 2018. doi:https://doi.org/10.2777/01532. https://www.sapea.info/wp-content/uploads/CCU-report-proof3-for-23-May.pdf [Accessed May 9, 2018.

14. Jacobson MZ. Abstracts of 30 peer-reviewed published journal articles supporting the result that the electric grid can stay stable with electricity provided by $100 \%$ or near-100\% renewable energy. 2017. http://web.stanford.edu/group/efmh/jacobson/Articles/l/CombiningRenew/ 100PercentPaperAbstracts.pdf. Accessed September 8, 2017.

15. Breyer C, Bogdanov D, Gulagi A, et al. On the role of solar photovoltaics in global energy transition scenarios. Prog Photovoltaics. 2017;25(8):727-745. https://doi.org/10.1002/pip.2885.

16. Breyer C, Bogdanov D, Aghahosseini A, et al. Solar photovoltaics demand for the global energy transition in the power sector. Prog Photovoltaics Res Appl. 2017. https://doi.org/10.1002/pip.2950;26(8):505-523.

17. Greenpeace \& European Renewable Energy Council. Energy [R] Evolution. Energy [R]Evolution. 2015:363. https://www.greenpeace.org/archive-international/en/campaigns/climate-change/energyrevolution/ . Accessed May 9, 2018.

18. Brown TW, Bischof-Niemz T, Blok K, Breyer C, Lund H, Mathiesen BV. Response to "Burden of proof: a comprehensive review of the feasibility of 100\% renewable-electricity systems". Renew Sustain Energy Rev. 2018;92:834-847.

19. Ram M, Bogdanov D, Aghahosseini A, et al. Global energy system based on 100\% renewable energy-power sector. Berlin and Lappeenranta; 2017. http:// energywatchgroup.org/wp-content/uploads/2017/11/Full-Study-100-Renewable-Energy-Worldwide-Power-Sector.pdf. Accessed March 26, 2018.

20. Scottish Development International. Wind Energy in Scotland. 2016. https://www.sdi.co.uk/knowledge-hub/articles/guide/offshore-renewables-supply-chain-guide. Accessed March 26, 2018.

21. Casey Z. Why is wind energy controversial despite favourable public opinion? Eur Wind Energy Assoc Blog. 2013. http://www.ewea.org/blog/2013/01/ why-is-wind-energy-controversial-despite-favourable-public-opinion/. Accessed August 9, 2017.

22. Sánchez A, Martín M. Optimal renewable production of ammonia from water and air. J Clean Prod. 2018;178:325-342. https://doi.org/10.1016/j. jclepro.2017.12.279

23. Hölling M, Weng M, Gellert S. Bewertung der Herstellung von Eisenschwamm unter Verwendung von Wasserstoff. Stahl Und Eisen. 2017;137(6):47-53.

24. Otto A, Robinius M, Grube T, Schiebahn S, Praktiknjo A, Stolten D. Power-to-steel: reducing CO2 through the integration of renewable energy and hydrogen into the German steel industry. Energies. 2017;10(4):451. https://doi.org/10.3390/en10040451

25. Georgiopoulou M, Lyberatos G. Life cycle assessment of the use of alternative fuels in cement kilns: a case study. J Environ Manage. 2017;15 (216):224-234.

26. Lund H. EnergyPLAN. Advanced energy system analysis computer model. Copenhagen: Aalborg Univeristy; 2015 http://www.energyplan.eu/. Accessed October 15, 2017.

27. Connolly D, Lund H, Mathiesen BV. Smart energy Europe: the technical and economic impact of one potential $100 \%$ renewable energy scenario for the European Union. Renew Sustain Energy Rev. 2016;60:1634-1653. https://doi.org/10.1016/j.rser.2016.02.025

28. Lund H, Mathiesen BV. Energy system analysis of $100 \%$ renewable energy systems-the case of Denmark in years 2030 and 2050 . Energy. $2009 ; 34$ (5):524-531. https://doi.org/10.1016/j.energy.2008.04.003

29. Connolly D, Mathiesen BV. A technical and economic analysis of one potential pathway to a $100 \%$ renewable energy system. Int J Sustain Energy Plan Manag. 2014;1:7-28. https://doi.org/10.5278/ijsepm.2014.1.2

30. Child M, Breyer C. Vision and initial feasibility of a recarbonized Finnish energy system. Renew Sustain Energy Rev. 2016;66:517-536. https://doi.org/ 10.1016/j.rser.2016.07.001

31. Child M, Nordling A, Breyer C. Scenarios for a sustainable energy system in the Åland Islands in 2030. Energ Conver Manage. 2017;137:49-60.

32. Meschede H, Child M, Breyer C. Assessment of sustainable energy system configuration for a small Canary island in 2030. Renew Sustain Energy Rev. 2018;165:363-372.

33. Connolly D, Lund H, Mathiesen BV, Leahy M. A review of computer tools for analysing the integration of renewable energy into various energy systems. Appl Energy. 2010;87(4):1059-1082. https://doi.org/10.1016/j.apenergy.2009.09.026

34. Lund H, Arler F, Østergaard PA, et al. Simulation versus optimisation: theoretical positions in energy system modelling. Energies. 2017;10(7). https://doi. org/10.3390/en10070840

35. Huld T, Müller R, Gambardella A. A new solar radiation database for estimating PV performance in Europe and Africa. Sol Energy. 2012;86 (6):1803-1815. https://doi.org/10.1016/j.solener.2012.03.006

36. Šúri M, Huld TA, Dunlop ED, Ossenbrink HA. Potential of solar electricity generation in the European Union member states and candidate countries. Sol Energy. 2007;81(10):1295-1305. https://doi.org/10.1016/j.solener.2006.12.007

37. Wikipedia contributors. List of power stations in Scotland. Wikipedia, Free Encycl. 2018. https://en.wikipedia.org/wiki/List_of_power_stations_in_Scotland. Accessed November 15, 2018.

38. Sample JE, Duncan N, Ferguson M, Cooksley S. Scotland's hydropower: current capacity, future potential and the possible impacts of climate change. Renew Sustain Energy Rev. 2015;52:111-122. https://doi.org/10.1016/j.rser.2015.07.071 
39. Andersen RS, Towers W, Smith P. Assessing the potential for biomass energy to contribute to Scotland's renewable energy needs. Biomass Bioenergy. 2005;29(2):73-82. https://doi.org/10.1016/j.biombioe.2005.04.004

40. Neill SP, Vögler A, Goward-Brown AJ, et al. The wave and tidal resource of Scotland. Renew Energy. 2017;114:3-17. https://doi.org/10.1016/j. renene.2017.03.027

41. Agora Energiewende. Comparing the cost of low-carbon technologies: what is the cheapest option? Rep by Progn AG. 2014. https://www.prognos.com/ fileadmin/pdf/publikationsdatenbank/140417_Prognos_Agora_Analysis_Decarbonisationtechnologies_EN.pdf. Accessed November 1, 2016.

42. Scottish Government. Energy in Scotland 2018-Data, Charts \& Sources. 2018. http://www.gov.scot/Topics/Statistics/Browse/Business/Energy/ElS/ EIS2018data. Accessed May 9, 2018.

43. Connolly D, Lund H, Mathiesen BV, Leahy M. The first step towards a 100\% renewable energy-system for Ireland. Appl Energy. 2011;88(2):502-507. https://doi.org/10.1016/j.apenergy.2010.03.006

44. Zakeri B, Syri S, Rinne S. Higher renewable energy integration into the existing energy system of Finland. Is there any maximum limit? Energy. 2014;92 (Part 3):244-259. https://doi.org/10.1016/j.energy.2015.01.007

45. Sinclair Knight Merz. Scottish Generation Scenarios and Power Flows. Newcastle upon Tyne; 2011. http://www.gov.scot/Resource/0039/00394230.pdf. Accessed August 9, 2017.

46. Scottish Renewables. Briefing summary: a new 2030 energy target for Scotland. Glasgow; 2016. http://www.scottishrenewables.com/publications/ briefing-new-2030-energy-target-scotland/. Accessed March 9, 2018.

47. Ove Arup \& Partners. Scenarios for Scottish Heat: Heat Pathway Scenarios Model Factual Report. London; 2014. http://www.gov.scot/Resource/ 0045/00451939.pdf. Accessed April 9, 2018.

48. Connolly D. EnergyPLAN Cost Database. 2017. http://www.energyplan.eu/models/costdatabase/. Accessed January 12, 2018.

49. Bogdanov D, Breyer C. North-east Asian super grid for $100 \%$ renewable energy supply: optimal mix of energy technologies for electricity, gas and heat supply options. Energ Conver Manage. 2016;112:176-190. https://doi.org/10.1016/j.enconman.2016.01.019

50. Stetter D. Enhancement of the REMix energy system model: global renewable energy potentials, optimized power plant siting and scenario validation. Ph D thesis, Institue of Thermodynamics and Thermal Engineering, University of Stuttgart, 2012. http://elib.uni-stuttgart.de/opus/volltexte/2014/ 9453/pdf/Dissertation_Stetter_Daniel.pdf. Accessed April 10, 2018.

51. Stackhouse P. Surface meteorology and solar energy (SSE). Release 6.0. National Aeronautic and Space Administration (NASA), Langley https://eosweb. larc.nasa.gov/sse/. Accessed November 17, 2014.

52. Verzano K. Climate change impacts on flood related hydrological processes: further development and application of a global scale hydrological model. Reports on Earth System Science, 71, Max-Planck-Institut für Meteorologie, Hamburg, Dissertation, Faculty of Electrical Engineering and Computer Science,University of Kessel, 2009.

53. Child M, Bogdanov D, Breyer C. The role of storage technologies for the transtion to a $100 \%$ renewable energy system in Europe. Energy Procedia. 2018; In press.

54. International Technology Roadmap for Photovoltaics (ITRPV). ITRPV Ninth Edition 2018 Including maturity report. Frankfurt; 2018. http://itrpv.net/ Reports/Downloads/. Accessed April 10, 2018.

55. Fasihi M, Bogdanov D, Breyer C. Long-term hydrocarbon trade options for the Maghreb region and Europe-renewable energy based synthetic fuels for a net zero emissions world. Sustainability. 2017;9(2):306. https://doi.org/10.3390/su9020306

56. Ferroukhi R, Khalid A, Lopez-Peña A, Renner M. Renewable energy and jobs: annual review 2015. Abu Dhabi; 2015. http://www.irena.org/publications/2015/May/Renewable-Energy-and-Jobs--Annual-Review-2015. Accessed April 18, 2018.

57. Wheatley S, Sovacool B, Sornette D. Of disasters and dragon kings: a statistical analysis of nuclear power incidents \& accidents. Risk Anal. 2015;1 (1):1-24. https://doi.org/10.1111/risa.12587.

58. Gilbert A, Sovacool BK, Johnstone P, Stirling A. Cost overruns and financial risk in the construction of nuclear power reactors: a critical appraisal. Energy Policy. 2017;102:644-649. https://doi.org/10.1016/j.enpol.2016.04.001

59. Wheatley S, Sovacool BK, Sornette D. Reassessing the safety of nuclear power. Energy Res Soc Sci. 2016;15:96-100. https://doi.org/10.1016/j. erss.2015.12.026

60. Watt H. Hinkley Point: the "dreadful deal" behind the world's most expensive power plant. The Guardian. https://www.theguardian.com/news/2017/ dec/21/hinkley-point-c-dreadful-deal-behind-worlds-most-expensive-power-plant. Published 2017. Accessed March $12,2018$.

61. Ćosić B, Krajačić G, Duić N. A 100\% renewable energy system in the year 2050: the case of Macedonia. Energy. 2012;48(1):80-87. https://doi.org/ 10.1016/j.energy.2012.06.078

62. McCrone A, Moslener U, D'Estais F, Grünig C. Global trends in renewable energy investment 2017. Frankfurt; 2017. http://fs-unep-centre.org/sites/ default/files/publications/globaltrendsinrenewableenergyinvestment2017.pdf\%0Ahttp://fs-unep-centre.org/publications/global-trends-renewableenergy-investment-2017. Accessed March 12, 2018.

63. Vakkilainen E, Helin T, Soukka R. Comparison of Finnish renewable energy targets and their effect on society. Lappeenranta; 2015. https://www. researchgate.net/publication/242262563_Comparison_of_Finnish_renewable_energy_targets_and_their_effect_on_society/overview. Accessed May $12,2018$.

64. Mathiesen BV, Lund H, Karlsson K. 100\% renewable energy systems, climate mitigation and economic growth. Appl Energy. 2011;88(2):488-501. https://doi.org/10.1016/j.apenergy.2010.03.001

65. Schellnhuber HJ, Rahmstorf S, Winkelmann R. Why the right climate target was agreed in Paris. Nat Clim Chang. 2016;6(7):649-653. https://doi.org/ 10.1038/nclimate3013.

66. Williamson P, Raper SCB, Wigley TML, Meinshausen M, Nakicenovic N, Schellnhuber HJ. Emissions reduction: scrutinize CO 2 removal methods. Nature. 2016;530(7589):153-155. https://doi.org/10.1038/530153a

67. Spreng D, Marland G, Weinberg AM. $\mathrm{CO}_{2}$ capture and storage: another Faustian bargain? Energy Policy. 2007;35(2):850-854. https://doi.org/10.1016/j. enpol.2006.10.009 
68. Leeson D, Mac Dowell N, Shah N, Petit C, Fennell PS. A techno-economic analysis and systematic review of carbon capture and storage (CCS) applied to the iron and steel, cement, oil refining and pulp and paper industries, as well as other high purity sources. Int J Greenh Gas Control. 2017;61:71-84. https://doi.org/10.1016/j.ijggc.2017.03.020

69. Bui M, Fajardy M, Mac DN. Bio-energy with CCS (BECCS) performance evaluation: efficiency enhancement and emissions reduction. Appl Energy. 2017;195:289-302. https://doi.org/10.1016/j.apenergy.2017.03.063

70. Alcalde J, Smith P, Haszeldine RS, Bond CE. The potential for implementation of negative emission technologies in Scotland. Int J Greenh Gas Control. 2018;76:85-91. https://doi.org/10.1016/j.jggc.2018.06.021

71. Child M, Nordling A, Breyer C. The impact of high V2G participation in a 100\% renewable Åland energy system. In: Energies. 2017; Article number 2206.

72. Weitemeyer S, Kleinhans D, Vogt T, Agert C. Integration of renewable energy sources in future power systems: the role of storage. Renew Energy. 2015;75:14-20. https://doi.org/10.1016/j.renene.2014.09.028

73. Bogdanov D, Breyer C. The role of solar energy towards $100 \%$ renewable power supply for Israel: integrating Solar PV, wind energy, CSP and storages. In: Proceedings of the 19th Sede Boger Symposium on Solar Electricity Production. Sede Boqer, February 23-25; 2015. http://bit.ly/2FmE6El.

74. Ridjan I, Mathiesen BV, Connolly D, Duić N. The feasibility of synthetic fuels in renewable energy systems. Energy. 2013;57:76-84. https://doi.org/ 10.1016/j.energy.2013.01.046

75. García-Olivares A, Solé J, Osychenko O. Transportation in a 100\% renewable energy system. Energ Conver Manage. 2018;158(January):266-285. https://doi.org/10.1016/j.enconman.2017.12.053

76. Horvath S, Fasihi M, Breyer C. Techno-economic analysis of a decarbonized shipping sector: technology suggestions for a fleet in 2030 and 2040 . Energ Conver Manage. 2018;164:230-241. https://doi.org/10.1016/j.enconman.2018.02.098

77. Connolly D, Mathiesen BV, Ridjan I. A comparison between renewable transport fuels that can supplement or replace biofuels in a $100 \%$ renewable energy system. Energy. 2014;73:110-125. https://doi.org/10.1016/j.energy.2014.05.104

78. Sterner M. Bioenergy and renewable power methane in integrated $100 \%$ renewable energy systems. Limiting global warming by transforming energy systems. PhD thesis, Faculty of Electrical Engineering and and Computer Science, University of Kassel, 2009. https://bit.ly/2LkWRYl. Accessed Feb ruary $1,2018$.

79. Henning HM, Palzer A. A comprehensive model for the German electricity and heat sector in a future energy system with a dominant contribution from renewable energy technologies-part I: methodology. Renew Sustain Energy Rev. 2014;30(2):1019-1034.

80. Pleßmann G, Erdmann M, Hlusiak M, Breyer C. Global energy storage demand for a 100\% renewable electricity supply. Energy Procedia. 2014;46:22-31. https://doi.org/10.1016/j.egypro.2014.01.154

81. Agora Energiewende. Stromspeicher in Der Energiewende. Berlin; 2014. http://www.speicherinitiative.at/assets/Uploads/19-AgoraEnergiewendeSpeicherstudie-Langfassung.pdf. Accessed February 1, 2018.

82. Breyer C, Tsupari E, Tikka V, Vainikka P. Power-to-gas as an emerging profitable business through creating an integrated value chain. Energy Procedia. 2015;73:182-189. https://doi.org/10.1016/j.egypro.2015.07.668

83. Götz M, Lefebvre J, Mörs F, et al. Renewable power-to-gas: a technological and economic review. Renew Energy. 2016;85:1371-1390. https://doi.org/ 10.1016/j.renene.2015.07.066

84. Tremel A, Wasserscheid P, Baldauf M, Hammer T. Techno-economic analysis for the synthesis of liquid and gaseous fuels based on hydrogen production via electrolysis. In. Int J Hydrogen Energy. 2015;40:11457-11464. https://doi.org/10.1016/j.ijhydene.2015.01.097

85. Bloombergy. Company Overview of Scotland Gas Netwroks plc. 2018. https://www.bloomberg.com/research/stocks/private/snapshot.asp?.privcapld= 26972759. Accessed May 21, 2018.

86. Scotland Gas Networks. SGN: who are we? 2018. https://www.sgn.co.uk/. Accessed May 31, 2018.

87. Schlachtberger DP, Becker S, Schramm S, Greiner M. Backup flexibility classes in emerging large-scale renewable electricity systems. Energ Conver Manage. 2016;125:336-346.

88. Salpakari J, Mikkola J, Lund PD. Improved flexibility with large-scale variable renewable power in cities through optimal demand side management and power-to-heat conversion. Energ Conver Manage. 2016;126:649-661. https://doi.org/10.1016/j.enconman.2016.08.041

89. Lund PD, Lindgren J, Mikkola J, Salpakari J. Review of energy system flexibility measures to enable high levels of variable renewable electricity. Renew Sustain Energy Rev. 2015;45:785-807. https://doi.org/10.1016/j.rser.2015.01.057

90. Zhang K, Xu L, Ouyang M, et al. Optimal decentralized valley-filling charging strategy for electric vehicles. Energ Conver Manage. 2014;78:537-550. https://doi.org/10.1016/j.enconman.2013.11.011

91. Panwar LK, Reddy KS, Kumar R, Panigrahi BK, Vyas S. Strategic energy management (SEM) in a micro grid with modern grid interactive electric vehicle. Energ Conver Manage. 2015;106:41-52. https://doi.org/10.1016/j.enconman.2015.09.019

92. Kiviluoma J. Managing wind power variability and uncertainty through increased power system flexibility. Aalto University: Doctoral thesis, School of Science; 2013 http://urn.fi/URN:ISBN:978-951-38-8006-4.

93. Morais $\mathrm{H}$, Sousa T, Vale Z, Faria P. Evaluation of the electric vehicle impact in the power demand curve in a smart grid environment. Energ Conver Manage. 2014;82:268-282. https://doi.org/10.1016/j.enconman.2014.03.032

\section{SUPPORTING INFORMATION}

Additional supporting information may be found online in the Supporting Information section at the end of the article.

How to cite this article: Child M, llonen R, Vavilov M, Kolehmainen M, Breyer C. Scenarios for sustainable energy in Scotland. Wind Energy. 2019;1-19. https://doi.org/10.1002/we.2314 